\title{
Food, feeding ecology and ecological segregation of seabirds at South Georgia
}

\author{
J. P. CROXALL AND P. A. PRINCE
}

\author{
Life Sciences Division, British Antarctic Survey, \\ Natural Environment Research Council, Madingley Road, \\ Cambridge CB3 OET, England
}

At the sub-Antarctic island of South Georgia 25 of the 29 breeding species are seabirds. Fifteen of these have recently been studied in some detail. By examining the timing of their breeding seasons and their diet and feeding ecology (especially feeding techniques and potential foraging ranges), the nature of their ecological isolating mechanisms, and in particular the way in which they partition the resources of the marine environment, are reviewed.

Although breeding season adaptations occur (winter breeding in Wandering Albatross and King Penguin; out of phase breeding in two species-pairs of small petrels) these are less important than diflerences in food and feeding ecology. There is a fundamental distinction between the niche of pursuit-diving species (mainly penguins) and the remainder which are basically surface-feeders. The two abundant krill-eating penguins show clear differences in feeding zones. Three albatrosses and a petrel feed mainly on squid and there are differences in both the species and size of the prey of each. The remaining seabirds chiefly take krill (although the giant petrels are extensive scavengers and some smaller petrels specialize on copepods) and utilize different teeding methods and areas to do so.

Various adaptations related to inshore and offshore feeding zones are discussed. Although most species possess a combination of ecological isolating mechanisms additional evidence for the particular importance of dietary differences is presented.

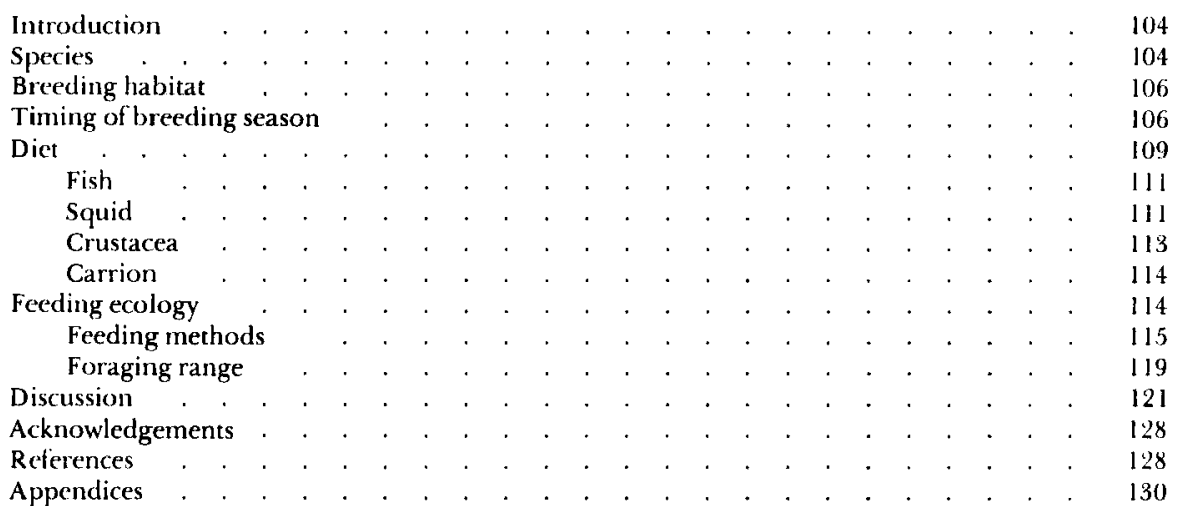


While the nature of ecological isolating mechanisms operating in multi-species seabird communities has received some attention in north temperate and tropical regions (e.g. Belopolskii, 1957; Ashmole \& Ashmole, 1967; Ashmole, 1968; Pearson, 1968; Cody, 1973) there has been no similar detailed investigation of any south temperate, sub-Antarctic or Antarctic situation although Carrick \& Ingham $(1967,1970)$ summarized much general information for Antarctic areas.

The southern oceans, particularly in the last two regions, are well known to be rich in plant and animal plankton and nekton and to support an extensive array of vertebrate predators including vast numbers of seabirds. At high latitudes, such as the periphery of the Antarctic continent, the exceptional seabird biomass is not matched by a comparable species diversity. At the sub-Antarctic islands, however, most of the considerable diversity of seabird species are present in substantial numbers. This circumstance is probably due to a combination of the rich upwelling areas around the islands' continental shelves and their proximity to the highly productive area of water mixing known as the Antarctic Convergence and to the very restricted amount of suitable land areas for breeding in these latitudes.

Although South Georgia is a little further south than the other islands usually classified as sub-Antarctic (e.g. Prince Edward Islands, Crozet Islands, Kerguelen Island, Macquarie Island) it still lies only $300 \mathrm{~km}$ south of the Antarctic Convergence. Of its 29 species of breeding birds (Prince \& Payne, 1979) there are 16 procellariforms (albatrosses, petrels etc.) five penguins and four other species (shag, skua, gull and tern) which derive all or part of their food from the sea.

In the last few years the biology and ecology of many of the albatrosses, petrels and penguins have been studied at Bird Island (a small island of $c .500$ ha off extreme north-west South Georgia) usually with particular emphasis on diet and feeding ecology. Although much of the research is still in progress this would seem a useful stage to summarize our present ideas on the morphological, behavioural, ecological and temporal mechanisms by which these species partition the resources of the surrounding marine environment.

\section{SPECIES}

A list of the main species to be discussed and an estimate of the size of their current breeding population at South Georgia and Bird Island is given in Table 1 ; selected measurements of these species appear in Appendix 1 and 2.

The Table, and most of what follows, is confined to procellariforms and penguins. We have only anecdotal information on the four species thus excluded; three (shag, gull and tern) breed only in very small numbers on Bird Island and all four appear to have very distinct ecological roles, each typical of its group, which overlap hardly at all either with each other or with the other seabirds. The Antarctic Tern feeds very close inshore, usually in sheltered water, by contact dipping (picking prey from the sea surface while momentarily halting Hight) or shallow plunging; Southern Black-backed Gull feeds mainly on marine organisms in the intertidal zone or close inshore waters; the Brown Skua is part scavenger (at fur seal and penguin colonies), part predator of small petrels, mainly at night; Blue-eyed Shag is chiefly piscivorous in water close inshore, 


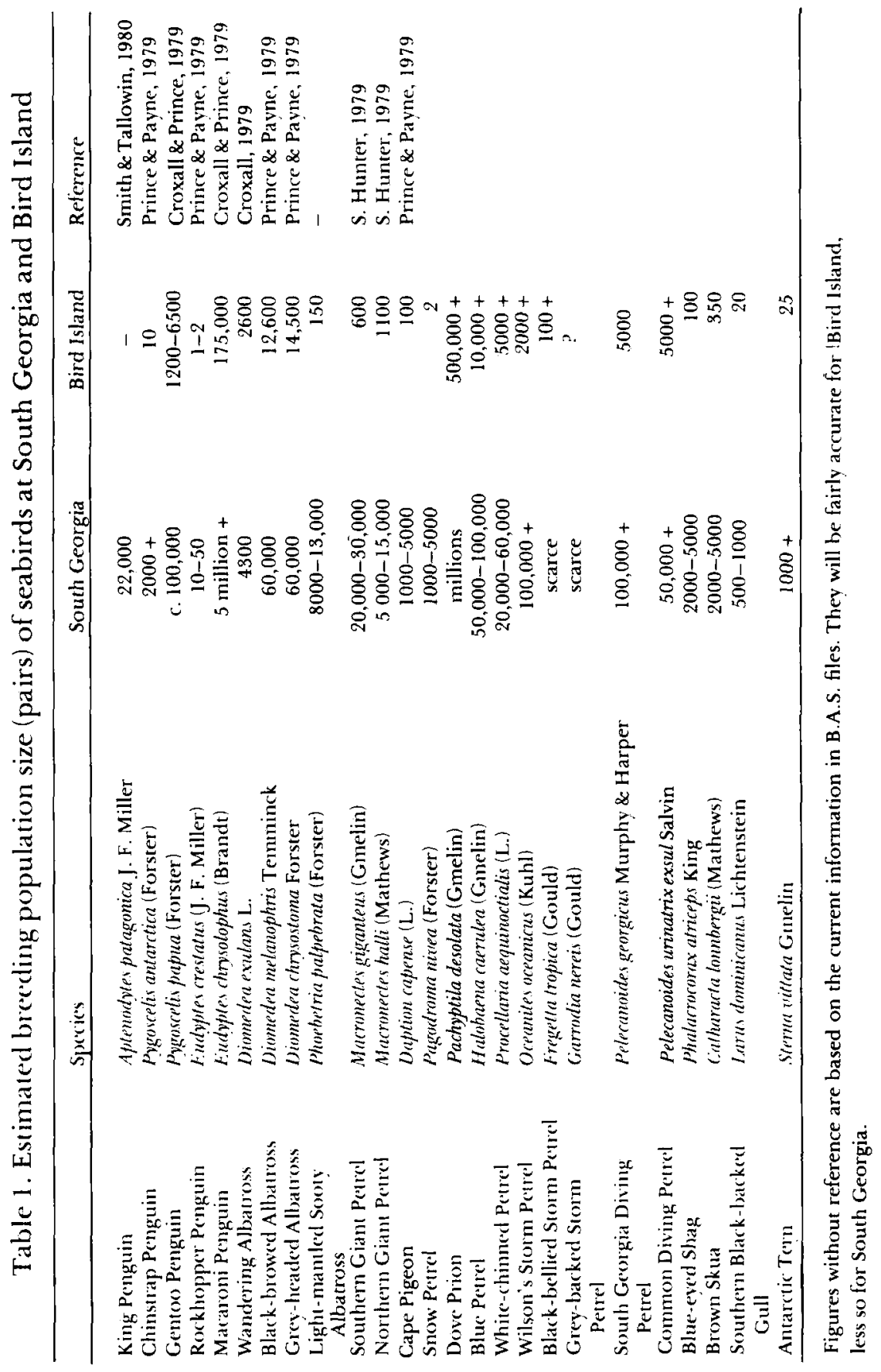


particularly around kelp beds although the population at Shag Rocks, $200 \mathrm{~km}$ west of South Georgia, must be considerably more oceanic in habit. These species will not be treated subsequently except where their ecological role appears relevant to the remaining species.

Table 1 shows also that there are six other species (Chinstrap and Rockhopper Penguins, Snow and Cape Petrels, Black-bellied and Grey-backed Storm Petrels) that are at best scarce breeding species at South Georgia. Except for Chinstrap Penguin we have little information even on their diet. Attention will therefore be focussed chiefly on the remaining 15 species, comprising three penguins, four albatrosses, five petrels, two diving petrels and a storm petrel.

\section{BREEDING HABITAT}

The existence of nest site preferences has been well described for northern hemisphere auks (e.g. Lack, 1934; Sergeant, 1951) and noted for other seabirds. Together with evidence for interspecific competition for nest sites (e.g. Belopolskii, 1957; Bedard, 1959a) such habitat segregation has been recognized as a significant ecological isolating mechanism, at least in situations where available breeding sites are in limited supply.

Some South Georgia seabirds show distinct habitat preferences when breeding and these are summarized, together with information on the nature of their breeding aggregations, in Table 2 . The ubiquity of the tussock grass Poa flabellata (Lam.) Hook. $f$. habitat, the dominant vegetation type, and its suitability as a substrate for burrowing petrels ensures that most species breed in this habitat. With the petrels and particularly the two diving petrels (see Payne \& Prince, 1979, for full details) it is possible often to recognize certain preferences of aspect, slope and microhabitat (cf. Richdale, 1965) and these are being investigated at Bird Island while census work on the burrow-dwelling species is in progress.

With no species has any form of interspecific nest site competition been observed. For all species there appear to be available extensive areas of fully suitable breeding habitat as yet unexploited and it is very difficult to believe that nest site availability has any significant effect on breeding population numbers. It is particularly notable that few species at South Georgia breed on cliffs. The absence of predators may be responsible for this contrast with the northern hemisphere where cliff nesting is such a feature of seabird biology.

There seem to be no obvious disadvantages attending the choice of particular breeding habitats as even the most inland sites are seldom more than a few hundred metres from the sea and most species-specific differences in site topography are probably interpretable in relation to species' morphological, behavioural and ecological adaptations.

\section{TIMING OF BREEDING SEASON}

Most South Georgia seabird species show very high synchrony of breeding events both within and between seasons. Egg laying is usually completed within two to three weeks and variation in laying date from season to season is often much less than this. This is not true for King Penguin (discussed in detail below), nor for Gentoo Penguin where, although each colony is fairly well synchronized, there may be considerable intercolony variation and a four to five week season to 
Table 2. Breeding habitat and dispersion of South Georgia seabirds

\begin{tabular}{|c|c|c|c|}
\hline Species & Breeding sites & $\begin{array}{c}\text { Breeding dispersion } \\
\text { and size }\end{array}$ & $\begin{array}{l}\text { Inter-nest } \\
\text { distance }\end{array}$ \\
\hline King Penguin & flat beaches & usually large colonies $\left(10^{\mathrm{s}}\right)$ & $1 \mathrm{~m}$ \\
\hline Chinstrap Penguin & beaches, slopes & medium colonies $\left(10^{2}-10^{3}\right)$ & $0.75 \mathrm{~m}$ \\
\hline Gentoo Penguin & $\begin{array}{l}\text { Hat beaches, } \\
\text { tussock }\end{array}$ & small colonies $\left(10^{2}\right)$ & $1 \mathrm{~m}$ \\
\hline Macaroni Penguin & $\begin{array}{l}\text { steep coastal } \\
\text { slopes }\end{array}$ & very large colonies $\left(10^{4}+\right)$ & $0.5 \mathrm{~m}$ \\
\hline Wandering Albatross & tussock Hats & loose aggregations & $10-20 \mathrm{~m}$ \\
\hline Grey-headed Albatross & tussock slopes & medium colonies $\left(10^{2}-10^{3}\right)$ & $1-2 \mathrm{~m}$ \\
\hline Black-browed Albatross & $\begin{array}{l}\text { steep tussock } \\
\text { slopes }\end{array}$ & medium colonies $\left(10^{2}-10^{3}\right)$ & $1-2 m$ \\
\hline $\begin{array}{l}\text { Light-mantled Sooty } \\
\text { Albatross }\end{array}$ & tussock cliffs & $\begin{array}{l}\text { solitary-small groups } \\
\quad(<10)\end{array}$ & $5-10 m$ \\
\hline Southern Giant Petrel & tussock flats & loose aggregations & $5-10 \mathrm{~m}$ \\
\hline Northern Giant Petrel & $\begin{array}{l}\text { tussock Hats } \\
\text { (often coastal) }\end{array}$ & loose aggregations & $5-10 \mathrm{~m}$ \\
\hline Cape Pigeon & $\begin{array}{l}\text { ledges of coastal } \\
\text { cliffs }\end{array}$ & small groups & - \\
\hline Snow Petrel & $\begin{array}{l}\text { crevices of high } \\
(300 \mathrm{~m} \text { a.s.l.) } \\
\text { inland cliffs }\end{array}$ & small groups & - \\
\hline Dove Prion & $\begin{array}{l}\text { tussock flats, } \\
\text { slopes }\end{array}$ & dense colonies & $1400 / 1000 \mathrm{~m}^{2}$ \\
\hline Blue Petrel & $\begin{array}{l}\text { tussock Hats, } \\
\text { slopes }\end{array}$ & $\begin{array}{l}\text { locally dense } \\
\text { colonies }\end{array}$ & $720 / 1000 \mathrm{~m}^{2}$ \\
\hline White-chinned Petrel & $\begin{array}{l}\text { tussock ridges, } \\
\text { hills, slopes }\end{array}$ & $\begin{array}{l}\text { locally dense } \\
\text { colonies }\end{array}$ & $40 / 1000 \mathrm{~m}^{2}$ \\
\hline Wilson's Storm Petrel & $\begin{array}{l}\text { coarse scree, } \\
\text { rubble, cliff } \\
\text { crevices }\end{array}$ & $\begin{array}{l}\text { medium colonies } \\
\qquad\left(10^{2}-10^{3}+\right)\end{array}$ & \\
\hline $\begin{array}{l}\text { South Georgia Diving } \\
\text { Petrel }\end{array}$ & $\begin{array}{l}\text { fine, high } \\
\text { (100-250 } \mathrm{m} \text { a.s.l.) } \\
\text { scree }\end{array}$ & small colonies $\left(10^{2}\right)$ & $200 / 1000 \mathrm{~m}^{2}$ \\
\hline Common Diving Petrel & $\begin{array}{l}\text { very steep } \\
\text { coastal tussock } \\
\text { slopes }\end{array}$ & $\begin{array}{l}\text { local medium colonies } \\
\left(10^{2}-10^{3}\right)\end{array}$ & \\
\hline
\end{tabular}

For burrow-dwelling species (below horizontal line) values are breeding densities (occupied burrows $/ 1000 \mathrm{~m}^{2}$ ) for optimum habitats (data from I. Hunter (1979) and pers. comm.).

season variation in laying date has been recorded. The storm petrels are probably also poorly synchronized, as at Signy Island (Beck, 1970), but there are insufficient data.

The average duration of the breeding season, from egg-laying to chick Hedging, of South Georgia penguins and petrels is shown in Fig. 1. This shows clearly that for most species the onset of breeding is October-November with Hedging February-March-April. The relative consistency of this pattern is, of course, a reflection of the strong seasonality of the environment with phytoplankton production virtually restricted to the period October-May with a single pronounced peak in the South Georgia area around early December (Hart, 1942) and mean zooplankton biomass in the 0-50 $\mathrm{m}$ depth zone rising steadily from October to a peak in April and returning to very low levels by July (Foxton, 1956; 1964).

In general terms the larger seabirds (e.g. albatrosses, giant petrels), with 


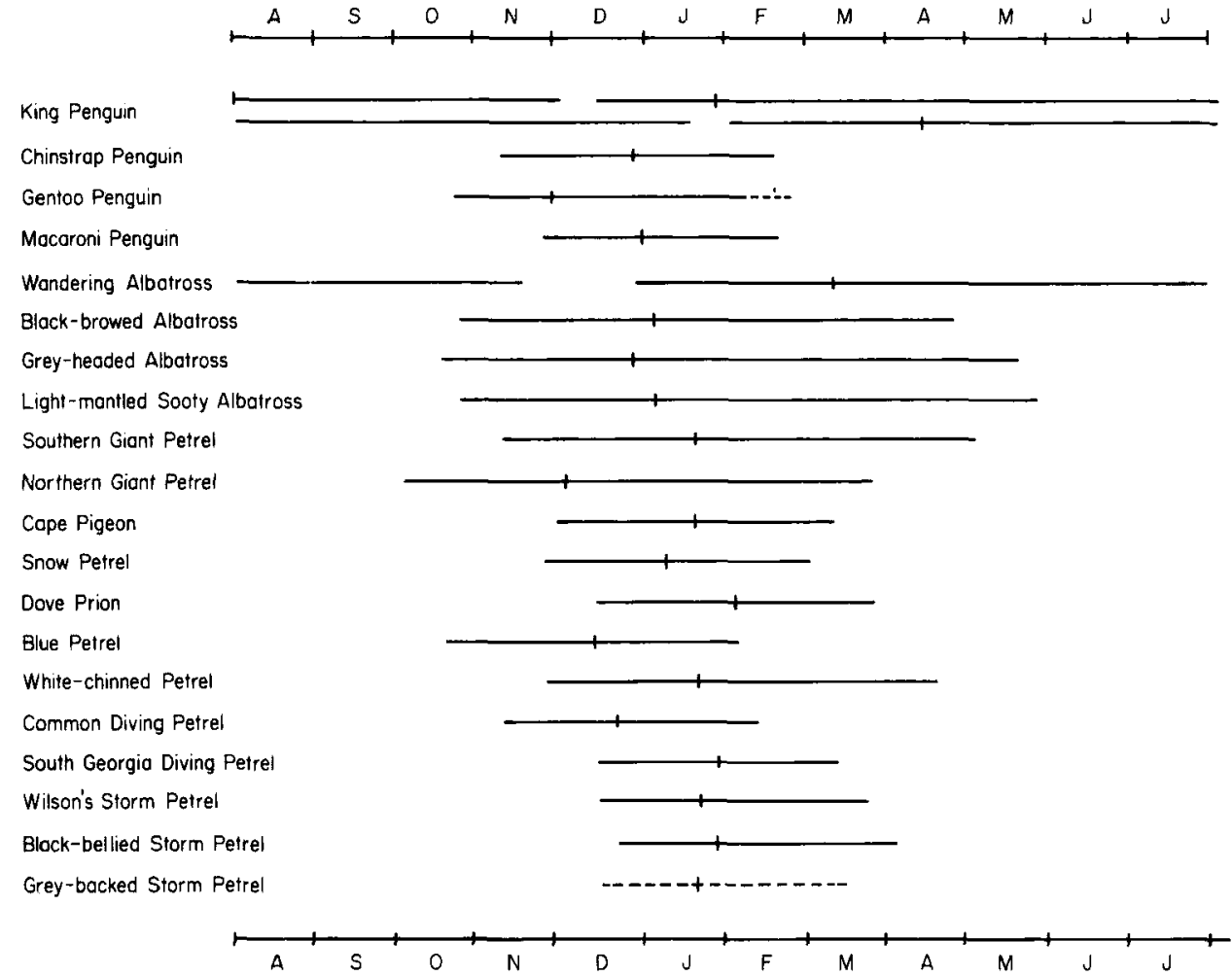

Figure 1. Breeding seasons of South Georgia seabirds. Horizontal lines run trom mean laying to mean Hedging date. Vertical bar is mean hatching date. Broken line indicates dates or period uncertain.

inevitably longer incubation and fledging periods, appear to commence breeding as soon as practicable (usually in October) apparently in order to ensure that chicks are fledged while rich supplies of zooplankton remain available. For smaller seabirds, with a shorter breeding season, it is clearly possible for its onset to be considerably delayed and fledging at an optimum period maintained.

In spite of the considerable similarities referred to there are two anomalous species and several other features of particular interest. At South Georgia Stonehouse (1960) found that breeding King Penguins usually follow a sequence of early breeding (laying in November-December, chick Hedging following November), late breeding (laying February-April, chicks fledging January-February) and non-breeding in three successive seasons, raising, at best, two chicks in this period. At Iles Crozet a somewhat similar situation prevails, although it appears that birds there may only breed successfully in alternate seasons (Barrat, 1976).

It has been suggested (Stonehouse, 1960) that this system has been adopted due to the inability of King Penguins to lay eggs before November which thus prevents chicks being fledged before June (at a time when food resources are dwindling to a minimum). The chicks are therefore sustained with sporadic feeds through the winter and fledge in early summer when food is plentiful; the parents can then return to breeding condition and lay in late summer but this 
chick, if it survives the high winter mortality, does not Hedge until mid-summer and the parents are now unable to commence breeding again that season.

Similar arguments (long chick fledging period in relation to resource availability) can be advanced to account for the Wandering Albatross rearing its chick with regular feeds throughout the winter. The chicks fledge in late November and adults that successfully raise a chick (and those that lose it after June) can only breed biennially (Tickell, 1968). In this context it should be noted that such greater than annual breeding periodicity is not associated solely with winter breeding species; Grey-headed and Light-mantled Sooty Albatrosses are both biennial breeders when successful (Tickell \& Pinder, 1967; Prince, unpublished data; Kerry, pers. comm. and in prep.).

The flexibility in timing of breeding season available to the smaller petrels has already been mentioned. In two cases it appears that this may have been used to reduce interspecific competition, particularly with respect to the time of greatest demands for food, i.e. when raising chicks. Thus, both for Dove Prion and Blue Petrel and for South Georgia and Common Diving Petrels, chick-rearing periods are virtually mutually exclusive.

Unfortunately, there are no data on timing of the breeding season for sites at which only one member of these 'species-pairs' breed, to indicate if an alternative breeding schedule is possible. At Signy Island, in the absence of Blue Petrel, Dove Prion commences breeding at a date similar to that on South Georgia (Tickell, 1960). However Signy Island is much further south and breeding probably starts as early as conditions permit (Beck, 1970). Other subspecies of Common Diving Petrel in the New Zealand area are likewise early breeders (Richdale, 1965; Thoresen, 1969) but there are several small petrels (though no other diving petrel) that breed later. While the staggered breeding seasons of the two sibling species of giant petrels, which consistently lay about six weeks apart, may chiefly function as a reproductive isolating mechanism (and even so hybrid pairs are occasionally reported (Burger, 1978; S. Hunter, 1979) it will be seen that this may also play a part in restricting the extent of direct competition for food.

\section{DIET}

A summary of the results of quantitative studies on the diet of South Georgia seabirds is presented in Table 3. Also included are estimates derived from earlier qualitative analyses where these have been confirmed by current observations. Data obtained farther south have been used for three species as our observations indicate that a similar situation prevails at South Georgia, where we lack fully quantitative information.

More comprehensive information can be found in the references indicated, in most of which details of the frequency of occurrence and number of individuals in each prey class are given. For the present purpose the weight data were thought to provide the most straightforward and relevant picture. Details of the various sampling and analytical techniques employed are given, principally in Prince (1980 a, b) and Croxall \& Prince (1980). In particular it should be noted that most samples were obtained from adults just about to feed their chicks, thus avoiding the problems of food accumulation that result if samples are taken from chicks. 


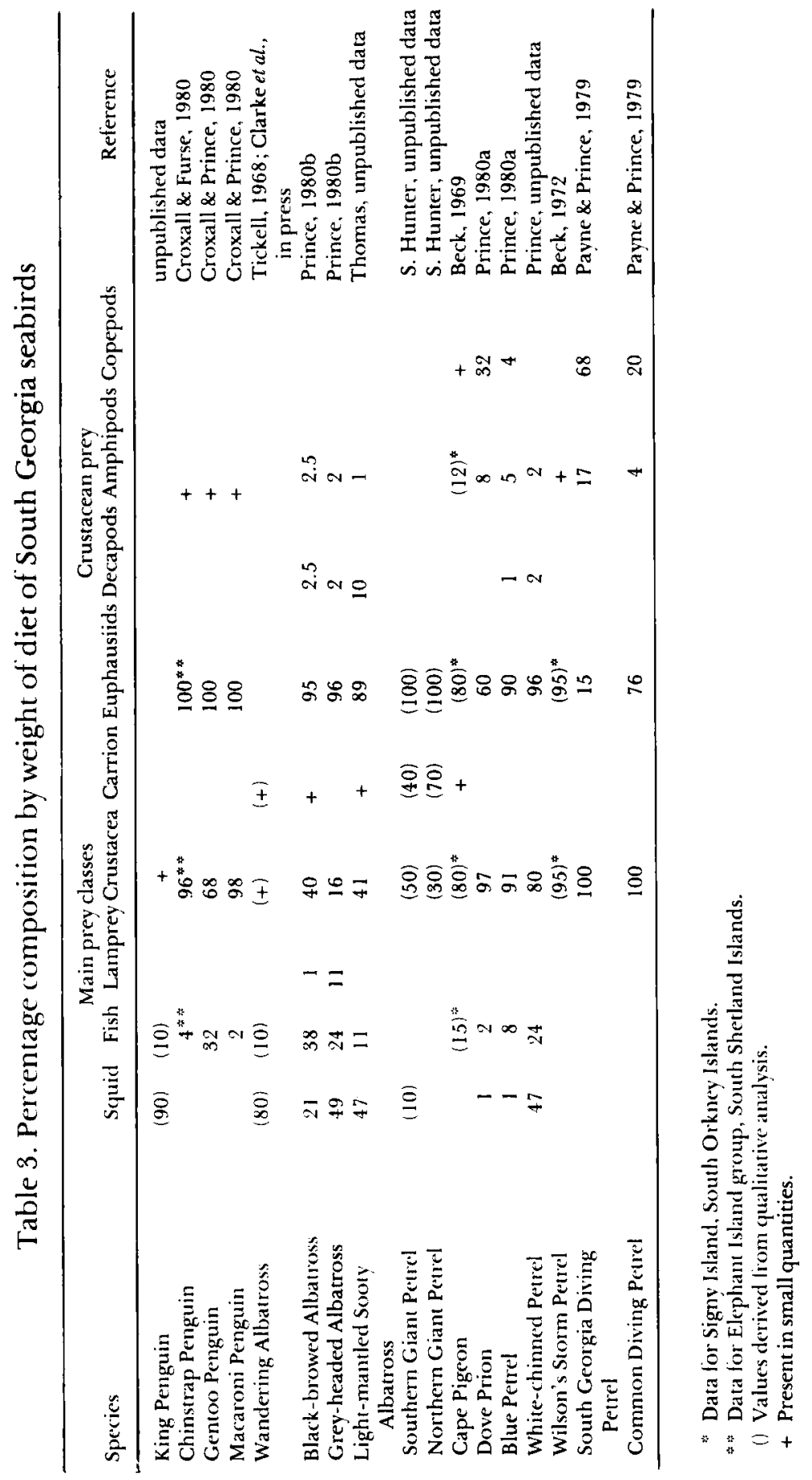


The basic breakdown of consumers in respect of the major prey classes can now briefly be summarized before the further segregation that may be achieved by feeding ecology is considered.

\section{Fish}

Fish are taken by many species in the Table but are the principal prey of none, although they almost certainly predominate in the diet of Blue-eyed Shag. Fish are important in the diet of Black-browed Albatross, Grey-headed Albatross, Gentoo Penguin and White-chinned Petrel and also for Blue Petrel. This last is not apparent from the table but Prince (1980a) noted that fish occurred in 83\% of samples and if the components of the highly digested totally unidentifiable material are (reasonably) attributed to fish then they would contribute $50 \%$ by weight to the diet and the crustacean contribution would be commensurately reduced.

Except in Gentoo Penguin, the condition of fish material has usually been insufficient for identification, other than at the family level of Myctophidae and Notothenidae and Pseudochaenichthys georgianus Norman (Chaenichthyidae) in some albatross samples. In the Gentoo Penguin material specimens of Notothenia rossii Richardson, $N$. larseni Lonnberg and Champsocephalus gunnari Lonnberg $c .25$ $\mathrm{cm}$ long were identified (Croxall \& Prince, 1980); $N$. gibberifrons Lonnberg 9-12 $\mathrm{cm}$ long has been recorded in a stomach examined at Signy Island (Conroy \&c Twelves, 1972). Blue Petrels take very small fish (and probably mainly myctophids) but it is not possible to discern any differences between the fish portion of the diet in the other species.

The presence of lampreys in the diet of Grey-headed Albatross (and hardly at all in Black-browed Albatross) is particularly noteworthy. The specimens were nearly mature individuals, probably just about to return to their South American breeding rivers (Potter, Prince \& Croxall, 1979), of Geotria australis Gray, a species only recorded hitherto in the diet of one other seabird, Black Petrel Procellaria parkinsoni Gray (Imber, 1976).

\section{Squid}

Squid appear fundamental to the diet of King Penguin and Wandering Albatross and very important as a food for Grey-headed Albatross, Light-mantled Sooty Albatross and White-chinned Petrel.

While we have no squid material for King Penguin and that for White-chinned Petrel is still being analysed it is possible to compare in more detail the composition of the squid portion of the diet of four albatrosses (the three mentioned above plus Black-browed Albatross) in Table 4. This table includes details of all squid species which formed more than $5 \%$ by numbers or weight of the squid diet of any of the albatrosses.

Some clear differences are apparent. Many squid species were recorded from Wandering Albatross but the bulk of its diet is made up by Kondakovia longimana of mean weight just over $3 \mathrm{~kg}$. Grey-headed and Black-browed Albatrosses mainly took Todarodes sagittatus of mean weight just under $200 \mathrm{~g}$. Mesonychoteuthis species (mean weight $80 \mathrm{~g}$ ) was the most abundant squid in Light-mantled Sooty Albatross samples but Discoteuthis (mean weight $c .700 \mathrm{~g}$ ) made up the bulk by weight. It would seem therefore that, with the exception of the very similar (in 


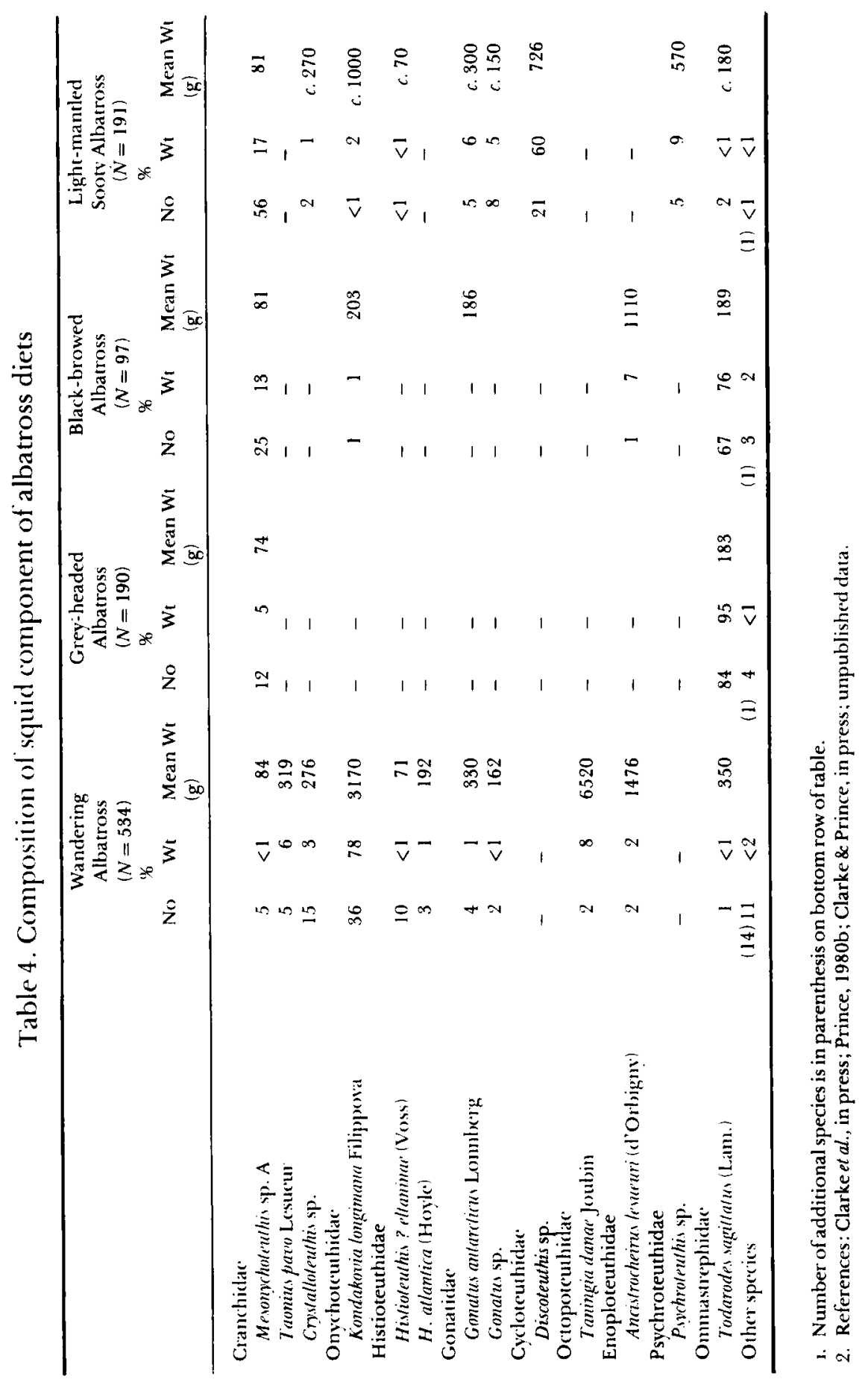


body and bill dimensions) Grey-headed Albatross and Black-browed Albatross (and squid is of small importance in the diet of the latter) the albatrosses take squid of both different species and sizes. There are, however, differences in the provenance of the samples. Although the Grey-headed Albatross and Blackbrowed Albatross data are directly comparable and largely comprise information from nearly complete squid from fresh samples, those for the two other species are derived from examination of regurgitated beaks, which in the case of Wandering Albatross must derive mainly from squid fed to the chick during the austral winter. Thus we do not know what squid this albatross feeds on when the other three are breeding (and vice versa). Nevertheless, even with these qualifications, the pattern of segregation of squid prey by species and size amongst three types of albatrosses seems a convincing one. White-chinned Petrels, not surprisingly, take mainly much smaller prey amongst which histioteuthids predominate and one or two larger genera like Taonius and Gonatus occur. They too would seem to be reasonably distinct from the other species in their squid prey.

Elsewhere giant petrels have been recorded to regurgitate squid (Conroy, 1972; Johnstone, 1977) and it was surprising that none were found in the small number of samples collected at Bird Island in 1978-79 (although a few beaks had been found in previous seasons). At Macquarie Island Johnstone (1977) reports Kondakovia longimana, Taonius, Gonatus and Histioteuthis? eltaninae, a combination that is reminiscent of Wandering Albatross squid diet, as well as Nototodarus sloani Gray, a species apparently particularly common in Australasian waters, and various less certainly identified taxa.

\section{Crustacea}

In contrast to squid, where the variety of species available may make it easier to achieve a degree of dietary segregation, the principal crustacean taken by nearly all birds is krill Euphausia superba Dana. Only in three species (Dove Prion and the two diving petrels) does it represent much less than $90 \%$ of crustacean biomass. For these three species copepods are the other main prey; they predominate by numbers in the diet of Dove Prion and even by weight in that of Common Diving Petrel, the latter thus contrasting quite strongly with the situation in South Georgia Diving Petrel where copepods are much less, and euphausiids much more, important.

Amphipods are ubiquitous, but probably often derive from the stomach contents of larger prey items; only in the smaller petrels are they probably a regular feature of the diet. Large decapods (chiefly Acanthephyra spp.) are taken mainly by albatrosses and larger petrels and appear to make a significant contribution to the diet of Light-mantled Sooty Albatross.

In squid the size of prey varied between predators but, in spite of the many bird species of different dimensions to which krill is important, most take mature krill of mean length $c .53-55 \mathrm{~mm}$. Blue Petrel and Dove Prion both took smaller Krill (mean length 45 and $41 \mathrm{~mm}$ respectively; (Prince, 1980a) and Macaroni Penguin took large numbers (but only $18 \%$ by weight) of small, probably 1 st year krill of mean length c. $20 \mathrm{~mm}$ (Croxall \& Prince, 1980). The broad picture, however, is clearly one of mature krill being of basic importance to the diet of all species (including Snow Petrel and Cape Pigeon which are not in Table 3) except 
King Penguin, Wandering Albatross, Grey-headed Albatross and perhaps Common Diving Petrel.

Nevertheless the minor components of the diet should not always be dismissed as totally insignificant. Careful analysis of the amphipods in the diet of Blue Petrel and Dove Prion showed that there were significant differences in the proportions taken of nearly all of the six species common to the diet of both birds (Prince, 1980a). This also provided some additional evidence for suggestions that some of the dietary differences might be due to prey selection (resulting from different feeding techniques) rather than changes in prey availability.

\section{Carrion}

Several seabirds are well known ship-followers, notably giant petrels, Wandering and Black-browed Albatrosses, Cape Pigeons and Wilson's Storm Petrels and the last two and Snow Petrel were common scavengers at whaling stations. It is doubtful nowadays if any of these species subsist to any significant extent upon items scavenged around ships.

Wandering Albatrosses may obtain some of their squid from material regurgitated by Sperm Whales Physeter catodon L. (see feeding ecology) and giant petrels certainly derive substantial food from around seal beaches and penguin colonies.

At South Georgia, and Bird Island in particular, the recent population explosion of Antarctic Fur Seal Arctocephalus gazella Peters (Payne, 1977) has had some interesting effects on the giant petrel population. Between 1973/74 and $1978 / 79$ the $M$. halli population has increased from fewer than 500 pairs to 1100 pairs, while $M$. giganteus has increased little, if at all (S. Hunter, 1979). This has coincided with the Bird Island fur seal beaches reaching maximum density and with a correlated substantial availability of placentae and pup carcasses in December-January. The difference in the timing of the breeding seasons of these two giant petrels means that such food is available during the chick rearing period only to $M$. halli and may be significantly implicated in the numerical increase of this species. The greater dependence of $M$. halli on beach carrion may also account for indications that $M$. giganteus feeds more at sea and takes a greater proportion of free-living food.

\section{FEEDING ECOLOGY}

With the small number of basic prey types available it is not surprising that the distinctions indicated in the previous section between the diet of most species relate to differences in the proportions of these main prey classes taken rather than to absolute prey-specific differences. There are several ways in which information on feeding ecology can contribute to further the picture of resource division and ecological segregation during the breeding season.

First, it may be possible to distinguish differences in species' feeding location, whether in terms of depth or area. Second, the use of particular feeding techniques may reinforce the dietary segregation by being closely correlated with predation of particular organisms. The main feeding methods of the seabirds involved are shown in Table 5. 
Table 5. Feeding methods of South Georgia seabirds

\begin{tabular}{|c|c|c|c|c|c|c|c|}
\hline Species & $\begin{array}{l}\text { Pursuit } \\
\text { dive }\end{array}$ & Plunge & Dive & $\begin{array}{c}\text { Methods } \\
\text { Surface } \\
\text { seize }\end{array}$ & Dip & Filter & Scavenge \\
\hline King Penguin & $\mathbf{x x x}$ & & & & & & \\
\hline Chinstrap Penguin & $\mathbf{x x x}$ & & & & & & \\
\hline Gentoo Penguin & $\mathrm{xxx}$ & & & & & & \\
\hline Macaroni Penguin & $\mathrm{xxx}$ & & & & & & \\
\hline Wandering Albatross & & & & $\mathrm{xxx}$ & & & $\mathrm{xx}$ \\
\hline Black-browed Albatross & & $\mathrm{x}$ & $\mathrm{x}$ & $\operatorname{xxx}$ & & & $x x$ \\
\hline Grey-headed Albatross & & $\mathrm{x}$ & $\mathbf{x}$ & $\mathbf{x x x}$ & & & $\mathbf{x}$ \\
\hline Light mantled Sooty Albatross & & $\mathrm{x}$ & $?$ & $\mathbf{x x x}$ & & & $\mathrm{x}$ \\
\hline Southern Giant Petrel & & & & $\mathbf{x x x}$ & & & $\mathrm{xxx}$ \\
\hline Northern Giant Petrel & & & & $\mathbf{x x x}$ & & & $\mathrm{xxx}$ \\
\hline Cape Pigeon & & & & $\mathbf{x x x}$ & & & $\mathbf{x x}$ \\
\hline Snow Petrel & & & & $\mathbf{x x x}$ & & & $\mathrm{x}$ \\
\hline Dove Prion & & & & $\mathbf{x x}$ & & $\mathbf{x x x}$ & \\
\hline Blue Petrel & & & $\mathbf{x x}$ & $\mathbf{x x}$ & $\mathbf{x x}$ & & \\
\hline Whitc-chinned Petrel & & & $\mathbf{x x x}$ & $\mathbf{x x x}$ & & & \\
\hline Common Diving Petrel & $\mathbf{x x x}$ & $\mathbf{x} \mathbf{x}$ & $\mathbf{x x}$ & $\mathbf{x x}$ & & & \\
\hline South Georgia Diving Perrel & $\mathbf{x x x}$ & $\mathbf{x x}$ & $\mathbf{x x}$ & $\mathbf{x x}$ & & & \\
\hline Wilson's Storm Petrel & & $\mathbf{x}$ & & & $\mathbf{x x x}$ & & $\mathbf{x}$ \\
\hline Black-bellied Storm Petrel & & $\mathrm{xx}$ & & & $\mathrm{xxx}$ & & $\mathbf{x}$ \\
\hline Grey-backed Storm Petrel & & $\mathbf{x x}$ & & & $\mathrm{xxx}$ & & \\
\hline Blue-eyed Shag & $\mathrm{xxx}$ & & & & & & \\
\hline Brown Skua & & & & & & & $\mathbf{x x x}$ \\
\hline Southern Black-backed Gull & & & & $\mathrm{xxx}$ & & & $\mathrm{xx}$ \\
\hline Antarctic Tern & & $\mathbf{x x x}$ & & & $\mathbf{x x x}$ & & \\
\hline
\end{tabular}

$\mathrm{xxx}$ : common, $\mathrm{xx}$ : occasional, $\mathrm{x}$ : rare

\section{Feeding methods}

The major division here is between the pursuit-diving species, whether wingpropelled like penguins and diving petrels or foot-propelled like Blue-eyed Shag, and the remainder which are essentially restricted to feeding at the surface of the water.

The penguins are clearly pre-eminently adapted for life as aquatic pursuitdivers. This ability to exploit the water column to a considerable depth must be a substantial advantage over surface restricted species, amply compensating for any reduction in horizontal foraging area consequent on their inability to fly. There are few data on diving depths e.g. Gentoo Penguin caught at $100 \mathrm{~m}$ in a trammel net; (Conroy \& Twelves, 1972) but it seems likely that the smaller species can easily feed at $100 \mathrm{~m}$. This would be consistent with the depth distribution of large krill concentrations (mainly above $150 \mathrm{~m}$ even during the day) and of the fish species taken by Gentoo Penguin (see p. 111). Recent experiments suggest that King Penguins may be able to reach $215 \mathrm{~m}$ (G. L. Kooyman, pers. comm.) which compares favourably with a maximum of $265 \mathrm{~m}$ recorded for Emperor Penguin (Kooyman, Drabek, Elsner \& Campbell, 1971). Blue-eyed Shag has been caught in nets at $25 \mathrm{~m}$ (Conroy \&c Twelves, 1972) and although diving times of up to 2.5 min have been recorded (Kooyman, 1975), comparable with some of those for the smaller penguins (see Conroy \& Twelves, 1972; Kooyman, 1975), it is doubtful if they have the same capacity for prolonged diving. The diving petrels are also specilalized for diving and swimming underwater, chiefly by reduction in wing 
Table 6 . Feeding frequency, flight speed and potential foraging range of South Georgia seabirds

\begin{tabular}{|c|c|c|c|}
\hline Species & $\begin{array}{l}\text { Feeding frequency } \\
\text { (days) }\end{array}$ & 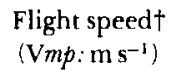 & $\begin{array}{c}\text { Foraging rangef } \\
(\mathrm{km})\end{array}$ \\
\hline Southern Giant Petrel & $<1$ & 12.5 & c. 350 \\
\hline Northern Giant Petrel & $<1$ & 12.5 & c. 350 \\
\hline Gentoo Penguin & 1 & 1.9 & 31.5 \\
\hline South Georgia Diving Petrel & $1+$ & 7.6 & 330 \\
\hline Common Diving Petrel & $1-1 \frac{1}{2}$ & 8.4 & 360 \\
\hline Wilson's Storm Petrel & $? 1-2$ & 5.7 & 250 \\
\hline Dove Prion & $1-2$ & 6.9 & 300 \\
\hline Macaroni Penguin & 2 & 1.9 & 115 \\
\hline Black-browed Albatross & 2 & 10.7 & 925 \\
\hline Grey-headed Albatross & 2 & 11.0 & 950 \\
\hline Blue Petrel & $2-3$ & 7.0 & 600 \\
\hline $\begin{array}{l}\text { Lightt-mantled Sooty } \\
\text { Albatross }\end{array}$ & 3 & 9.7 & 1250 \\
\hline White-chinned Petrel & 4 & 9.5 & 1650 \\
\hline Wandering Albatross & $5-6$ & 12.2 & 2650 \\
\hline King Penguin & ? $5-6$ & 1.9 & c. 500 \\
\hline
\end{tabular}

"Feeding frequency is interval between successive feeds to chick by same parent.

$\dagger$ Flight and swimming speeds calculated as described in text.

¥ Foraging range calculated on basis of higher feeding frequency.

length so that a 'paddle-like' condition for underwater propulsion is attained (Kuroda, 1967). This has decidedly impaired their flying ability and the species have very high flight speeds (Table 6) and wing loadings, a low buoyancy index (Appendix 2) and a relationship between wing areas and body mass very different from other procellariforms but similar to that of auks Alcidae which they so closely resemble (Warham, 1977: fig. 1). They are certainly not deep divers and may penetrate only a few metres below the sea surface. White-chinned Petrel is probably the only other species that regularly feeds below the surface and then only on very shallow surface dives.

In essence then only penguins, diving petrels and a shag depend on sub-surface foraging techniques. In contrast nearly all albatrosses and petrels take prey at the surface but there are so few field observations that it is not possible to say if there are any variations in the techniques used by different species. There are, however, a few species which mainly detect prey while in flight and either execute a shallow plunge to catch it (Antarctic Tern) or stoop to secure it while still in flight. In the latter category come the very different feeding methods of Wilson's Storm Petrel (pattering over the wave tops) and Blue Petrel (stooping from some height in a manner more typical of the gadfly petrels Pterodroma spp.).

Ainley (1977) has indicated that feeding methods may broadly relate to buoyancy indices (see Appendix 2). In Antarctic seabirds there is a much smaller range of such values $(2.5-4.0)$ compared with temperate and tropical species $(2.0-5.5)$. The low values for diving petrels are an integral part of the adaptations for diving and the high ones for storm petrels accord well with the association of such values with the 'dipping' method of feeding (see Ainley, 1977: table 1). Rather surprisingly Blue Petrel has a relatively low buoyancy value but its very low wing loading may be a compensation.

Giant petrels and albatrosses show uniformly low values, except for Lightmantled Sooty Albatross which is recognized as the most aerially adapted of 

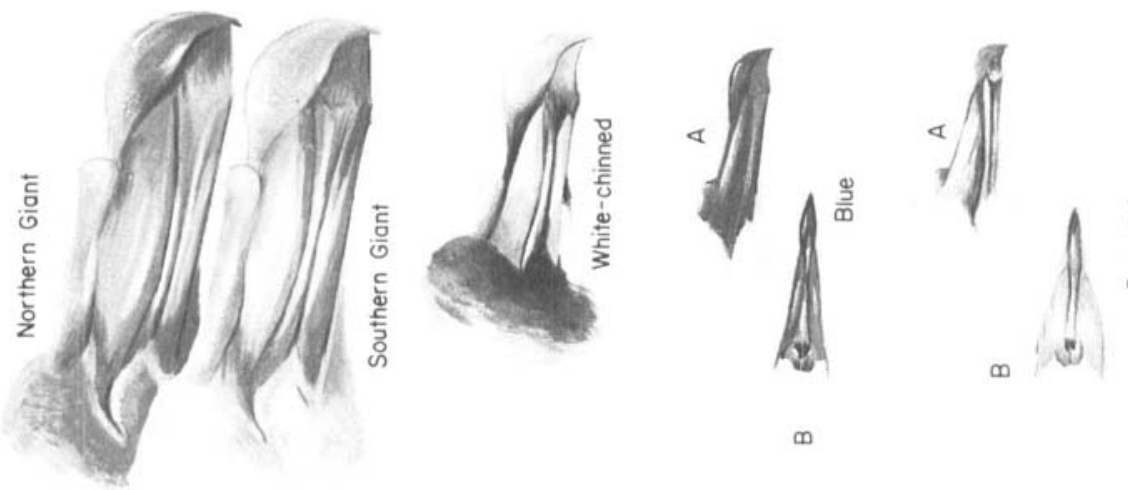

导总焉

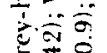

एँّ

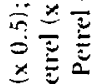

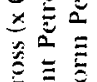

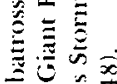

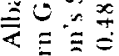

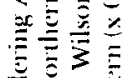

$\infty$

范茫

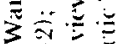

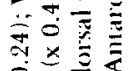

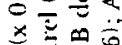
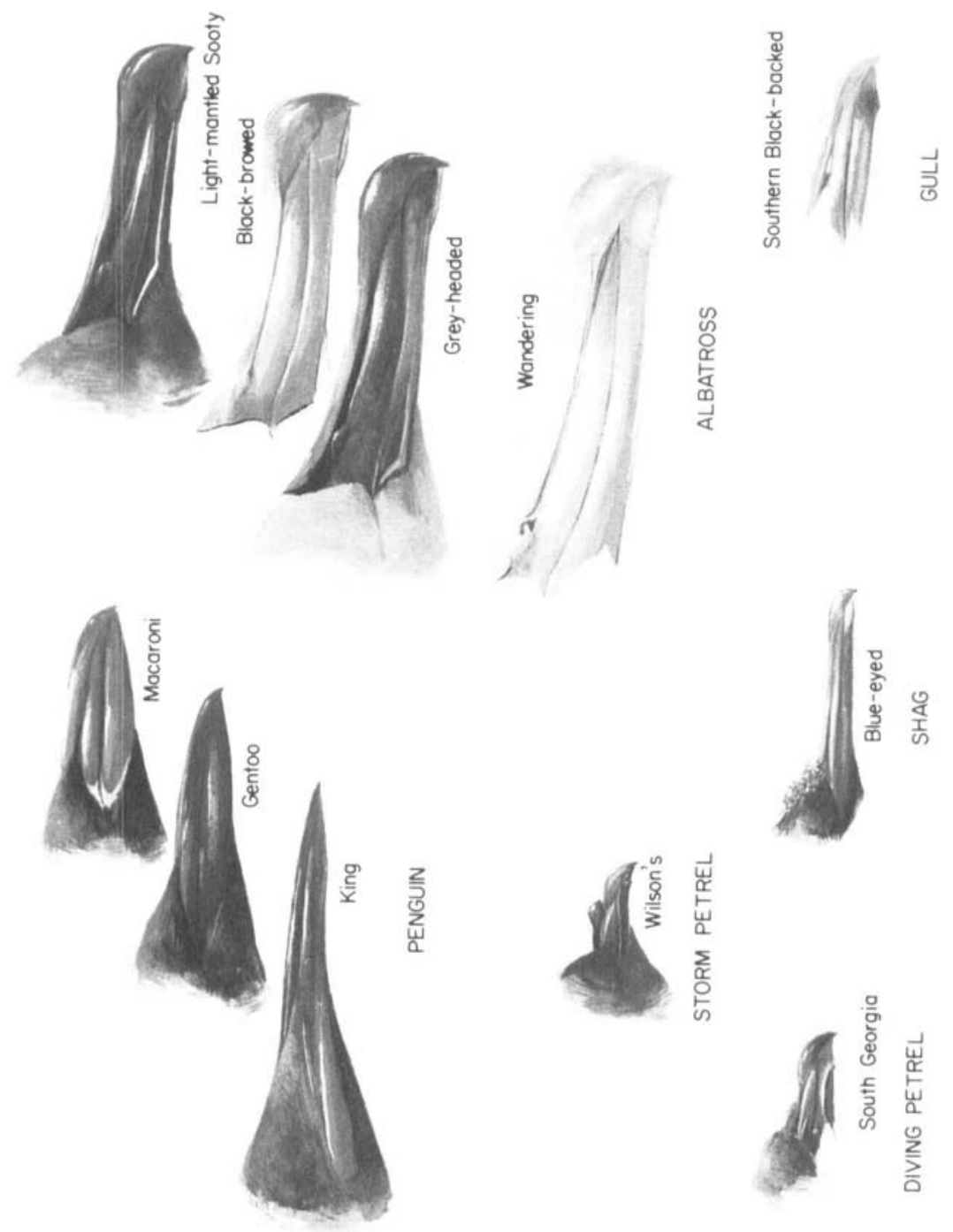

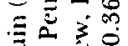

政

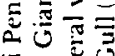

可
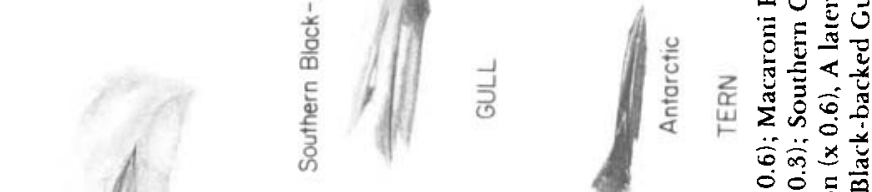

$\Sigma \dot{0} 0$

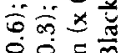

$\times \times$.

至

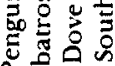

字苍菂

苟 $\frac{1}{2}$

$\therefore$ 吾

突电

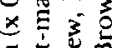

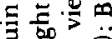

क्ष०

前焉

$x<\frac{x}{0}$

$\pm \underline{0}=$

मी

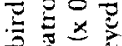

可焉

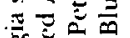

引马े

논

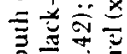

总范

万茄齐

象灾志

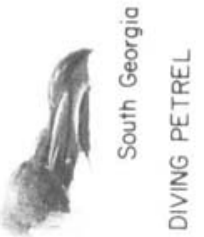

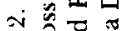

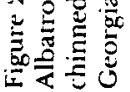


albatrosses, although it is unknown what relationship, if any, this has to its feeding methods. It may be noteworthy that the two small fulmarine petrels, Cape Pigeon and Snow Petrel, have rather different indices.

Finally the distinctive feeding technique of Dove Prion is particularly notable whereby, whether hydroplaning (wings outstretched, head just below the surface, propulsion from the feet) or swimming, small prey organisms are filtered by expelling the volume of water taken into the broad, deep bill (see Appendix 2, Fig. 2) through the lamellae fringing the inside of the upper mandible (see Prince, $1980 \mathrm{a}$ : plate I). It is this technique that makes it possible to capture vast quantities of small organisms-for example the 41,000 copepods in a food sample weighing only $16 \mathrm{~g}$ (Prince, 1980a). The employment of a specialized feeding apparatus thus permits Dove Prion to take substantial quantities of a vastly abundant prey that is clearly quite uneconomic for the other petrels, with bills adapted for picking and seizing, to exploit. In turn a feeding strategy like dipping is probably associated with the capture of larger prey, i.e. those which can be seen while the seabird is in flight. For nearly all prey items Blue Petrel was indeed shown to take larger (and usually significantly so) individuals than Dove Prion (Prince, 1980a). There is also a striking difference in wing loading between Blue Petrel and Dove Prion (see Appendix 2) which is not offset by differences in estimated Hight speed (Table 6) and suggests that Blue Petrel uses less energy per unit distance which would fit with its greater dependence on aerial feeding techniques.

Giant petrels, which feed extensively on carrion, seem well adapted for this with relatively short, deep and presumably very powerful bills for tearing tlesh from carcasses and it is possible that the flattened occiput of their skull represents an adaptation for inserting the head into carcasses.

The species that mainly use surface seizing techniques show a wide variation in bill size and shape (see Appendix 2, Fig. 2). Ashmole (1968) discussed extensively the relationships between bill size and shape and prey size in five species of sympatric tropical terns. Four of these species had bills of very similar lengths but differed more in depth (and hence cross-section area) and there was some correlation between bill stoutness and prey size although this was complicated by the influence of body size whereby smaller birds (with bill not always in proportion) tended to take very much smaller prey.

Here, although there are probably some relationships between bill shape and prey type (e.g. Gentoo with its more dagger-shaped bill being the small penguin which takes significant fish in its diet), there is little indication of correlation between bill size and crustacean prey size, although large decapods (especially Acanthephyra) seem principally to be taken by the larger petrels and albatrosses and copepods by the smaller petrels. There is insufficient information on tish dimensions to do other than confirm that petrels take much smaller prey than penguins and albatrosses. The differences in the dimensions of squid taken by albatrosses have already been noted, with Wandering Albatrosses taking many squid of mean weight $3 \mathrm{~kg}$, Grey-headed and Black-browed Albatrosses squid of c. $200 \mathrm{~g}$ (although some individuals of up to $1200 \mathrm{~g}$ were found) and Lightmantled Sooty Albatross a combination of squid weighing $80 \mathrm{~g}$ and $c .700 \mathrm{~g}$. It is not clear why the latter, which is the smallest albatross, regularly takes squid substantially larger than those taken by the slightly larger mollymauks. Equally it has been noted elsewhere (Clarke et al., in press) that $3 \mathrm{~kg}$ Kondakovia are 
themselves active, very well-armed predators and an albatross must be very adept to take such squid alive. It is certain that Wandering Albatrosses do scavenge the remains of some squid (e.g. of $6 \mathrm{~kg}+$ Taningia) probably from sperm whale vomit and it might be suggested that Kondakovia (and the Discoteuthis in Light-mantled Sooty Albatross diet) are taken in a similar manner. Evidence for and against this has been presented by Clarke $e t$ al. (in press) and we believe that, on balance, the long, powerful, razor-sharp and hook-tipped bills of these albatrosses are sufficiently effective to immobilize even quite large squid once they are impaled.

This in turn raises the question of how such active species as squid and fish can be approached by birds feeding at the surface and, apart from occasional records of surface plunging by mollymauks, there are no direct observations. It seems likely to us that squid and fish are often associated, as predators, with krill swarms and that as these rise to the surface (vertical migration) at night the predators accompany them and become available to petrels and albatrosses sitting, essentially invisible from below, on the surface.

The topic of nocturnal feeding by seabirds on vertically migrating marine organisms was reviewed by Imber (1973) who also drew attention to the high numbers of bioluminescent squid and fish (especially myctophids) taken by certain sea-birds and suggested that these prey were detected by their nocturnal light emissions. As more squid are bioluminescent than not and most have downwardly directed photophores, bioluminescent species may not, in fact, be especially vulnerable. Concentrations of bioluminescent krill may, however, be particularly visible and attractive to night-feeding seabirds - both krill-feeding species and those that gather in anticipation of catching the associated predators.

Although all seabirds will presumably take suitable prey at whatever time of day it is available, diurnal feeding on live prey has been recorded for few species. To judge either from times of chick feeding or actual observations it may be of some importance to Cape Pigeon, Snow Petrel, giant petrels (which are unusual in feeding chicks both by day and night ( $S$. Hunter, 1979)), Dove Prion and Wilson's Storm Petrel, although these last two do not feed their chicks until after dusk, presumably to reduce predation by skuas.

Pursuit-diving species would be expected to be much less restricted to nocturnal feeding than the surface feeders. It is not surprising, therefore, that all penguins regularly spend the night ashore in the colony on the conclusion of a feeding trip and proportionately must spend much more time feeding diurnally than nocturnally, especially while raising chicks. Thus a fundamental difference in feeding ecology (diving versus surface feeding) may also be associated, to some extent, with different temporal patterns of predation.

\section{Foraging range}

Species with similar breeding seasons, diets and foraging methods may still be adequately separated ecologically, if there is sufficient difference in their feeding zones. Examples of this have been provided by Ashmole \& Ashmole (1967) for two tropical terns Anous stolidus (L.) and Sterna fuscata L. and Cody (1973) for a number of northern hemisphere auks. In both these cases much of the evidence rested on field observations of feeding birds but, as noted earlier, there are few such observations of Antarctic seabirds and especially so for birds of known breeding status and provenance. 
In the absence of such intormation the interval between successive teeds brought to a chick by one parent can be used as an index of the distance travelled to find food. In Table 6 the species are arranged in order of increased duration of foraging trips (and therefore decreased frequency of feeding chicks).

In this paper we have chosen to use rather broad time categories for feeding frequency. For a number of the species we have much more precise data on the frequency with which a chick is fed, either derived from direct observations or the use of electronic recording devices in burrows to record the visits of parents, or from series' of chick weighings at $3 \mathrm{~h}$ intervals to detect feeds more accurately. Unfortunately we do not yet have such information for all the species concerned, nor are data from each source fully compatible. Pending a more thorough evaluation of all features of relevant data we have used simplified categories here, which may well mask some interspecific differences.

The species range from those where each parent feeds the chick daily (Gentoo Penguin usually has two chicks; all other species have only one) to those in which each parent may be absent for nearly a week. If there is any discontinuity in the distribution of species by foraging range it probably lies between species in which both parents feed chicks daily (e.g. giant petrels, diving petrels, often Dove Prion and probably Wilson's Storm Petrel) and those where each parent tends to feed the chick no oftener than on alternate days. This might represent a distinction between inshore and offshore feeding species and what few field observations exist would tend to contirm this. Thus all species in the first group are not infrequently seen feeding by land-based observers; none of the other species have ever been so observed at South Georgia.

In the absence of additional information it is impossible to make further subdivision (e.g. into a coastal-inshore-offshore-pelagic sequence) that might relate to the location of certain hydrographic features, e.g. continental shelf $(c .75 \mathrm{~km}$ wide), Antarctic Convergence c. $300 \mathrm{~km}$ distant. It is clear that some species (e.g. Wandering Albatross, White-chinned Petrel, Light-mantled Sooty Albatross) have the capacity for highly pelagic foraging and this is certainly supported by the presence of a number of squid in the diet of Wandering Albatross associated with warmer waters to the north of the Antarctic Convergence (Clarke et al., in press).

It is possible to gain a rough idea of potential foraging ranges of these species by considering the length of absence on a feeding trip together with flight (or swimming for penguins) speed. Using the method of Pennycuick (1969), values for minimum power speed, Vmp (essentially speed at which fuel is used most slowly and probably near the lower limits of a bird's flight speed range) have been derived using body weight data from Appendix 2 and wing span values mainly from Warham (1977) supplemented by unpublished data for Blue Petrel and South Georgia Diving Petrel. Kooyman (1975) suggested that penguins usually swim at $7-10 \mathrm{~km} \mathrm{~h}^{-1}$ and the lower value has been used to obtain the range estimates given here.

It should be stressed that these estimates are probably far from accurate, perhaps especially for the inshore species, as they assume a straight, direct flight path and no stops for feeding. In spite of these deficiencies it is instructive to examine the findings for taxonomically and ecologically related species.

Feeding range information has not shown up any obvious distinctions between the two Diomedea mollymauks, the two giant petrels (although there is 
circumstantial evidence that $M$. giganteus spends more time at sea than $M$. halli) or the two diving petrels (although Payne \& Prince (1979) from a detailed analysis of chick weight changes, noted that $P$. georgicus chicks are fed more assiduously than those of $P . u$. exsul). The largest and smallest albatrosses would appear to be more pelagic than the others.

The potential for Blue Petrel to feed further from the breeding site is indicated and this is supported (Prince, 1980a) by more detailed evidence from chick weighings, the occurrence of South Shetland Island derived pumice in the stomachs of $40 \%$ of Blue Petrels but only $2 \%$ of Dove Prions and the occurrence of twice as much oil (product of digestion of solid food) in Blue Petrel samples.

The difference between the two penguins is even more striking with average feeding trips of Gentoo usually lasting c. $9 \mathrm{~h}$ and those of Macaroni $c .33 \mathrm{~h}$. This inshore: offshore distinction is supported by the fish taken by Gentoo (see p. 111) belonging to the size classes of species which are known to frequent inshore kelp beds during maturation and by the much greater degree of digestion of krill of the same size in Macaroni samples than in Gentoo (Croxall \& Prince, 1980). It is also plausible that Gentoo, seeking to raise two chicks, should be more restricted in its foraging range than Macaroni with only a single offspring.

A little additional information can be deduced from general observations of birds at sea during the breeding season. The overall distribution of records indicates that Light-mantled Sooty Albatrosses, in contrast to the other albatrosses, are rarely seen to the north of South Georgia and that Blue Petrel also has a distinct southerly bias to its records. This may provide some indication of a directional bias in foraging activity that could not be deduced from information on mean foraging distance and it is interesting that the two most pelagic albatrosses should differ quite markedly in this respect.

We do not, of course, have any direct evidence of the use of different feeding areas or zones by those species with similar dietary requirements and breeding seasons and the possibility that the 'offshore' species merely collects food more slowly over the same general area as the 'inshore' one can only be regarded as inherently unlikely (and unsupported by the appropriate visual observations).

On the other hand Macaroni penguins certainly catch some krill close to land on their return trips as the top few krill in the stomach are usually hardly digested. Nevertheless they must be subject to less direct competition once out of the range of Gentoo Penguins and in terms of swimming efficiency it would make sense to do this journey with as little extra body weight as possible.

We have already noted that there are numerous warmer-water squid in the diet of Wandering Albatross, indicative of lengthier trips to the north of South Georgia, than in the food of the other Diomedea spp. With better knowledge of the local distribution of marine stocks we might be able to interpret the occurrence of small E. superba only in Macaroni samples or lampreys only in Grey-headed Albatross samples in terms of feeding areas.

\section{DISCUSSION}

In this paper we have tried to describe the biology and adaptations of South Georgia seabirds in relation to their ecological segregation in the breeding season and in particular to the way in which the resources of the marine environment are partitioned. 
It seems clear that temporal, dietary and geographical distinctions are each important and, indeed, it seems unlikely that any one mechanism by itself is adequate to achieve a sufficient degree of reduction in direct competition, if all species in the seabird community are considered together. Thus although Wandering Albatross breeds in winter it is likely that it takes different squid from other albatrosses even at other times of year. The diving petrels and the Blue Petrel-Dove Prion species pair have non-overlapping periods of chick rearing but, in addition, they have some clear differences in diet and associated adaptations. The two smaller penguins differ partly in diet and partly in feeding range. In citing these examples we are looking at the most similar pairs of species and only for the giant petrels (which are presently being studied) can we not yet see well-marked ecological differences.

We would re-emphasize, however, that the species of the community employ all of the main mechanisms in different combinations and proportions and that as a whole the community makes up a complex, dynamic pattern of interacting adaptations many facets of which still remain to be understood. In Table 8 we have set out in simplified diagrammatic form what we consider to be the way in which the more important ecological isolating mechanisms operate.

Unlike tropical seabirds where substantial diversity in the timing of breeding seasons is shown (Harris, 1969; Schreiber \& Ashmole, 1970), in high latitudes there is little room for manoeuvre. At South Georgia winter breeding is an unusual strategy with Wandering Albatross its chief exponent, as the time of principal demand for food by King Penguin populations is almost certainly in summer. At this time, however, it is the only real subsurface avian squid predator but it may well be in substantial competition earlier in the season with Southern Elephant Seal Mirounga leonina L. which also eats squid and fish. The feeding activity of the large South Georgia population of this seal (170,000 tonnes biomass by 1960 (Laws, 1960) and certainly over 200,000 tonnes nowadays) before and during its August-October breeding season may compel King Penguin to delay the onset of breeding.

The distinction between diving and surface feeding is clearly a fundamental one and it is doubtful if there is much competition between members of the two categories, particularly as there are likely to be differences in the time of day when much of the predation occurs.

The subsurface feeders appear segregated chiefly by diving capacity and diet but it would be interesting to know to what extent the large fur seal population $(369,000$ seals with a biomass of 14,500 tonnes (Payne, 1979) at South Georgia (and particularly Bird Island), compete with the small penguins. This fur seal seldom dives below $68 \mathrm{~m}$ (G. L. Kooyman, pers. comm.) and its prey is principally krill, some fish and a little squid.

For Gentoo and Macaroni Penguins, and a number of surface-feeding seabirds, differences in foraging range seem significant. The distinction between inshore and offshore feeding seabirds is often regarded as an important one and correlated with certain other biological adaptations of the species concerned. Thus Lack (1968) suggested that in many families of marine birds offshore feeders breed in larger more widely spaced colonies, have smaller clutches, longer incubation and fledging periods, longer incubation shifts, reduced chick feeding frequency but higher chick peak weights relative to adult weights and later sexual maturity compared with inshore feeders and that the differences are 
principally related to food availability. Cody (1973) added slower growth rates, and feed size a smaller proportion of adult body weight from his studies of northern hemisphere auks where he regarded differences in feeding zones as the principal ecological isolating mechanism.

In addition, on the basis of data for two storm petrels Oceanodroma, Ainley et al. (1975) suggested that the lower wing loadings of offshore feeders may be adaptive in reducing the energy used per unit distance flown. The wing loadings of Dove Prion and Blue Petrel (Appendix 2) are in line with this but Warham (1977) has noted that lower wing loading is usually correlated with slower flight speed which may be a countervailing disadvantage and the whole topic clearly needs critical re-investigation.

Finally it is worth noting that the poorly synchronized breeding species (Gentoo Penguin, storm petrels, see p. 106) all seem to be inshore feeders and perhaps worth speculating whether this asynchrony in breeding timetable may be an adaptive mechanism for reducing intraspecific competition in the restricted inshore waters by spreading the peak demand for food more evenly over a longer period.

It is of interest briefly to see to what extent the information presented here corroborate the general picture developed by Lack (1968). Some additional relevant data are given in Table 7, with the species still placed in order of feeding frequency. Although some of the meal size data are very approximate (and derived variously from interpretation of food sample and chick growth increment data) there is no indication of any fixed relationship between it and body weight (cf. Cody, 1973) and only the diving petrel values (derived from chick growth increment analysis) stand out as anomalous and it remains to be seen if this persists when other species' diets are analysed similarly.

Likewise there is no clear relationship between feeding zone and growth rate. However, if Cody's (1973) data are reanalysed relative to the size of the bird (rather than just as absolute weight increases), as his smaller species (with smallest absolute growth but high relative growth) were feeding farthest from land there is no correlation for his species either. Equally, nothing clear cut can be derived from the data on the amount by which chicks at peak weight exceed adult weight, a statistic reflecting the extent of fat reserves and hence the degree to which the chicks are insured against variations in feeding frequency, likely to be greatest in offshore foraging birds.

At the level of the 'species-pair', however, one is able to see some of the logic behind the earlier generalizations. Thus, in contrast to the inshore feeding Gentoo Penguin, the offshore feeding Macaroni Penguin breeds in few, vast colonies (no need to reduce the intraspecific competition that would be generated by excessive clumping of inshore feeders) has only one not two chicks, has month-long incubation periods not daily changeovers, makes fewer, longer feeding trips (though the single chick gets fed daily just as do those of Gentoo) and probably does not breed until at least six years of age (Carrick, (1972) on another subspecies, Royal Penguin E. chrysolophus schlegeli Finsch) whereas if Gentoo is similar to its congeners it may commence breeding at three years of age (Le Resche \&c Sladen, 1970; Ainley, 1975; Ainley \& De Master, in press). On the other hand incubation periods are similar and Macaroni chicks have faster growth and much shorter fledging periods. Many of these adaptations probably relate to the different requirements imposed by trying to raise two chicks rather 


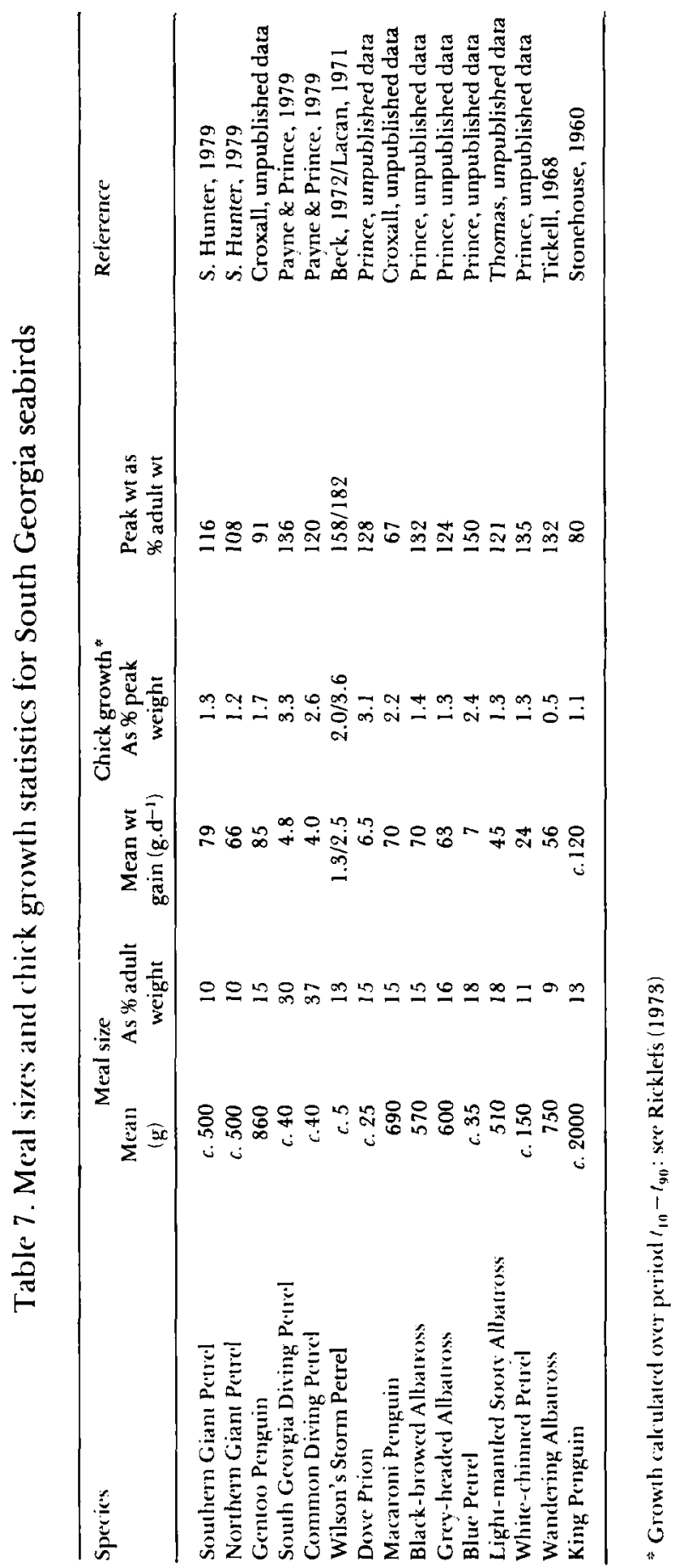


than one and can perhaps be seen as ecologically alternative strategies. It is not clear, however, what the significance is of the extremely long incubation and brooding shifts in Macaroni Penguin.

The later sexual maturity in Macaroni Penguin might be explained by postulating greater intraspecific competition for food amongst the breeding (and potentially breeding) population thus favouring a delay in first breeding attempts. A rough indication that this might be so is obtained by calculating the volume of ocean available to each individual of the breeding population of each species at South Georgia (see Table 1) within the estimated foraging range (Table 6) and for a feeding depth of $100 \mathrm{~m}$, assuming a circular feeding area around a point source. For Gentoo the result is $1558 \times 10^{3} \mathrm{~m}^{3}$ per bird whereas for Macaroni it is only $419 \times 10^{3} \mathrm{~m}^{3}$ per bird. Thus although the Macaroni Penguin population has over 13 times the sea volume at its disposal their 50 times greater abundance more than offsets this advantage.

Comparing the inshore Dove Prion with the more offshore Blue Petrel is somewhat less convincing as, against predictions, the latter is less abundant, has shorter incubation and fledging periods (but does show longer incubation shifts) and less frequent chick feeding (but larger feeds). With the two mollymauks meal size, feeding frequency, incubation shifts and incubation periods and abundance are similar (at South Georgia: Black-browed Albatross is much more abundant on a world population basis), and only the duration of the fledging and pre-laying attendance periods are different. Nevertheless Black-browed Albatross breeds at an earlier age and annually thereafter whereas Grey-headed Albatross breeds later and biennially when successful in raising a chick.

Thus in examining more closely three species-pairs we find, compared with predictions, reasonably good fits (penguins), poor fits (petrels) and species where major biological differences are barely indicated by differences in the range of adaptations surveyed. This is not to challenge the theoretical basis on which the generalizations rest nor their heuristic value nor the fact that all of them are supported by some species in some situations. It is rather to emphasize that with some Antarctic species we may have reached the stage where it will be possible, and preferable, on the basis of improved knowledge of appropriate details of the species' biology, to understand some of the key interrelationships between adaptations and ecological strategies, rather than to generate modified generalizations.

There is, both throughout the paper and in Table 8, a considerable emphasis on the importance of diet and its associated adaptations. This is partly because feeding studies form much of our work at South Georgia and partly because we believe that insufficient detailed quantitative attention has been given to this topic. For instance we wonder whether, if Cody had had available comprehensive dietary information (of the kind produced by Bedard (1969b) for three Alaskan auklets), he would have still maintained the over-riding importance of feeding zone separation.

We recognize that our own dietary data derive, in most cases, only from a single season's work and it may therefore be premature to regard them as fully typical. Nevertheless we would affirm the view, implicit in many of Lack's (1968) seabird analyses, that a knowledge of feeding ecology may be the key to understanding many other adaptations; in particular we believe that detailed knowledge of dietary composition by weight and nutritive value, of meal size and 
Table 8. Principal mechanisms for ecological segregation in the breeding season for South Georgia seabirds

\begin{tabular}{|c|c|c|}
\hline Winter & & Summer \\
\hline Diving & & Diving \\
\hline \multirow[t]{7}{*}{ King Penguin } & Inshore & \\
\hline & Fish: & Blue-eyed Shag \\
\hline & & Gentoo Penguin \\
\hline & Krill: & Gentoo Penguin \\
\hline & Offshore & \\
\hline & Krill: & Macaroni Penguin \\
\hline & Squid: & King Penguin \\
\hline Surface Feeding & & Surface Feeding \\
\hline \multirow[t]{13}{*}{ Wandering Albatross } & Squid: & White-chinned Petrel \\
\hline & & Light-mantled Sooty Albatross \\
\hline & & Grey-headed Albatross \\
\hline & Copepods: & Common Diving Petrel \\
\hline & & Dove Prion \\
\hline & Krill & \\
\hline & Inshore: & Common Diving Petrel (early) \\
\hline & & South Georgia Diving Petrel (late) \\
\hline & & Wilson's Storm Petrel \\
\hline & & Dove Prion \\
\hline & Offshore: & Blue Petrel \\
\hline & & Black-browed Albatross \\
\hline & Carrion: & Giant Petrels \\
\hline
\end{tabular}

feeding frequency in relation to chick growth rates are fundamental elements within this.

In saying this we imply that there may be important relationships between the above factors and it is appropriate here briefly to mention how they relate to the main differences between the two mollymauks (see p. 125). Prince (in prep.) has shown, particularly by following the growth of chicks raised from eggs by parents of the opposite species, that the difference in fledging times between these two species is principally due to differences in the composition of the diet fed to the chicks (the squid that predominates in Grey-headed Albatross diet being a much less nutritive resource than the krill which forms the bulk of Black-browed Albatross diet). It is likely also that the predominantly squid diet is implicated in the inability of successful Grey-headed Albatrosses to regain breeding condition in time to lay the following season. Thus, differences in dietary composition may be involved in fundamental differences in breeding strategy.

It has been implicit throughout this paper that most of the identified differences between species are the result of competition in the past and subsequent attempts by the birds to minimize the continuing effects of this. Some authors (e.g. Salomonsen, 1955; Beck, 1970) have contended that the abundance of suitable food is such that seabirds do not compete but most workers have been more impressed by the consequences of seasons of food shortage (Belopolskii, 1957; Ashmole, 1963, 1971; Croxall \& Prince, 1979) and have concluded that it is often the availability of appropriate prey rather than its actual existence or abundance that is the critical factor.

As with most similar analyses direct evidence of interspecific competition is lacking and much of the circumstantial evidence (the exact nature of the ecological differences, evidence for the selection of certain prey items when 
others are available and being taken by other species) has elements of circularity in its reasoning.

In 1977-78, however, commercial fishing operations around South Georgia were unable to locate krill in swarms and there was an unprecedented failure of krill-eating seabirds, especially Gentoo Penguin and Black-browed Albatross, to raise their chicks (Croxall \& Prince, 1979). In contrast Grey-headed Albatrosses, feeding mainly on squid (which themselves may have been feeding extensively on the astonishingly abundant amphipod Parathemisto gaudichaudii Guérin Meneville) had their best breeding season. It would appear significant that Blackbrowed Albatrosses, which do take squid, were unable sufficiently to switch to this resource to improve their breeding success and not implausible that direct competition with predominantly squid-eating Grey-headed Albatrosses may have been responsible.

This analysis has been exclusively concerned with the ecological picture during the breeding season. The lack of data on diet in winter makes it difficult to comment on the basis of segregation at that season. All species undoubtedly range much more widely once breeding is concluded. Diversity in the area is reduced as several species depart, notably Wilson's Storm Petrel, a migrant to the northern hemisphere, and Black-browed Albatross, moving north to warmer waters, chiefly off South Africa (Tickell, 1967). Some species, e.g. giant petrels, diving petrels, Gentoo Penguins, as well as Cape Pigeon and Snow Petrel, are seen at South Georgia throughout the winter and others such as Grey-headed Albatross certainly remain in high latitudes. There are thus indications that one member of at least two species-pairs may be considerably more migratory than the other. In the case of the albatrosses and the penguins the species that remains is that least dependent on euphausiid prey, a resource of minimal availability in winter, in contrast to squid and fish which are able to sustain breeding Wandering Albatrosses and King Penguins.

None of this information gives any indication whether competition for food for any of these species is more intense in summer or winter. The heavy demands during chick rearing (and particularly for penguins where a complete moult necessitating the development of enormous fat reserves immediately follows), lead us to think that the summer period may be the most critical.

Finally, why are certain South Georgia seabirds distinctly uncommon as breeding species and why do some other species not occur there? Although Rockhopper and Macaroni Penguins are probably respectively warmer and colder water replacement species they co-exist at Macquarie Island and at Marion Island. It is not clear why Rockhopper is not commoner at South Georgia unless the large population of Gentoo Penguins offers too much competition in inshore areas. The abundance of the two small penguins may also be restricting the expansion of Chinstrap Penguin (see Croxall \& Kirkwood, 1979) which takes krill and is probably somewhat intermediate in its foraging range (Croxall \& Furse, 1980). It may be significant that Chinstrap is most abundant at the southeast end of the island, where there is a much smaller concentration of Macaroni Penguins.

The small fulmarine petrels (Cape Pigeon and Snow Petrel) and the other storm petrels are all at a limit of their breeding range at South Georgia but it is uncertain why they are not more abundant. Cape Pigeon is a particular puzzle as it is abundant in the area in both summer and winter yet the breeding population is very small. 
At more northerly subantarctic islands (e.g. Crozet, Marion) a slightly greater diversity of seabirds than at South Georgia does occur. The additional species can be divided into three categories:

(a) warmer water congeners of the colder water species, e.g. Sooty Albatross Phoebetria fusca (Hilsenberg) and various prions Pachyptila (some with and some without the filtering lamellae), the prions often with some differences in breeding habitat and timing of the breeding season,

(b) gadfly petrels Pterodroma spp., a group typical of warmer water and specializing in in 'dipping' feeding techniques,

(c) winter breeding medium-sized petrels (e.g. Grey Petrel Procellaria cinerea Gmelin and Great-winged Petrel Pterodroma macroptera (A. Smith)).

All the additional species seem to derive from the greater proximity of these slightly more northerly islands to warmer waters and perhaps from the generally milder climate giving a longer effective breeding season and permitting a greater variety of species to breed in winter.

However it is probable that the marine environment surrounding these islands may not be as rich in food resources as the South Georgia area and it would be of great interest to know how the abundance and ecology of the typically subAntarctic species are affected under these circumstances.

\section{ACKNOWLEDGEMENTS}

We should like to thank Dr D. G. Ainley, Dr M. R. Clarke, I. Hunter, S. Hunter and G. Thomas for making available their unpublished data, Drs K. R. Kerry and G. L. Kooyman for allowing us to use their personal communications and Drs R. M. Laws and C. M. Perrins for comments on the manuscript. We are most indebted to Bruce Pearson for providing Fig. 2.

\section{REFERENCES}

AINLEY, D. G., 1975. Development of reproductive maturity in Adelie Penguins. In B. Stonehouse (Ed.), The Biology of Penguins: 139-157. London: Macmillan.

AINLEY, D. G., 1977. Feeding methods in seabirds: a comparison of polar and tropical nesting communities in the castern Pacific Ocean. In G. A. Llano (Ed.), Adaptations within Antarctic Ecosysiems: 669-685. Washington: Smithsonian Institution.

AINLEY, D. H. \& DEMASTER, D. P., in press. Survival and mortality in a population of penguins. Ecologv.

AINLEY, D. G., MORRELL, S., LEWIS, T. J., 1974. Patterns in the life histories of storm petrels on the Farallon Islands. Living Bird, 13:295-312.

ASHMOLE, N. P., 1963. The regulation of numbers of tropical oceanic birds. 16is, 103b:458-473.

ASHMOLE, N. P., 1968. Body size, prey size, and ecological segregation in five sympatric tropical terns (Aves: Laridael, Systematic Zoology, 17: 292-304.

ASHMOLE, N. P., 1971. Seabird ecology and the marine environment. In D. S. Farner and J. R. King (Eds.) Avian Biology, Vol. $1: 112-286$. New York: Academic Press.

ASHMOLE, N. P. \& ASHMOLE, M. J., 1976. Comparative feeding ecology of sea birds of a tropical oceanic island. Bulletin of the Peabody Museum of Natural History, 24:1-131.

BARRAT, A., 1976. Quelques aspects de la biologie et de l'écologie du Manchot royal (Aptenodytes patagonica) de l'ile de la Possession, archipel Crozet. Comite National Français des Récherches Antarctiques, No. 40:9-52.

BECK, J. R., 1969. Food, moult and age of first breeding in the Cape Pigeon, Daption capensis Linnaeus. British Antartic Survey Bulletin, No. 21: 33-44.

BECK, J. R., 1970. Breeding seasons and moult in some smaller Antarctic petrels. In M. W. Holdgate (Ed.), Antarctic Ecology: 542-550. London: Academic Press.

BECK, J. R. \& BROWN, 1972. The biology of Wilson's Storm Petrel Oceanites oceanicus (Kuhl), at Signy Island, South Orkney Islands. Scientific Report of the British Antarctic Survey, No. 69:1-54. 
BEDARD, J., 1969a. Histoire naturelle du Gode, Alca torda L., dans le golfe Sainı Laurent, Province de Québec, Canada. Etude de Service Canadien de la Faune, No. 7. Ottawa.

BEDARD, J., 1969b. Feeding of the Least, Creasted and Parakeet Auklets around St. Lawrence Island, Alaska. CanadianJoumal of Zoology, 47: 1025-1050.

BELOPOLSKII, L. O., 1957. Ecology of Sea Colony Birds of the Barents Sea. Israel Program of Scientific Translations, 1961

BURGER, A. E., 1978. Interspecific breeding attempts by Macronectes giganteus and M. halli. Emu, 78; 234-5.

CARRICK, R., 1972. Population ecology of the Australian Black-backed Magpie, Royal Penguin and Silver Gull. In Population Ecology of Migratory Birds: A Symposium. U.S. Department of the Interior Wildlife Research Report, No. 2: $41-99$.

CARRICK, R. \& INGHAM, S. E., 1967. Antarctic sea-birds as subjects for ecological research. Proceedings of the Symposium on Pacific-Antarctic Sciences, Tokyo, 1966. JARE Scientific Report, Spper. 1: 151-184. Tokyo: Department of Polar Research.

CARRICK, R. \& INGHAM, S. E., 1970. Ecology and population dynamics of antarctic seabirds. In M. W. Holdgate (Ed.), Antartic Ecology: 505-525. London: Academic Press.

CLARKE, M. R. \& PRINCE, P. A., in press. Cephalopod remains in regurgitations of Black-browed and Greyheaded Albatrosses at South Georgia. British Antarctic Survey Bulletin.

CLARKE, M. R., CROXALL, J. P. \& PRINCE, P. A., in press. Cephalopod remains in regurgitations of the Wandering Albatross at South Georgia. British Antarctic Survey Bulletin.

CODY, M. L., 1973. Coexistence, coevolution and convergent evolution in seabird communities. Ecology, 54: $31-44$.

CONROY, J. W. H., 1972. Ecological aspects of the biology of the giant petrel Macronectes giganteus (Gmelin) in the Maritime Antarctic. Scientific Report of the British Antarctic Survey, No. 75; 1-74.

CONROY, J. W. H. \& TWELVES, E. L., 1972. Diving depths of the Gentoo Penguin (Pygoscelis papua) and Blueeyed Shag (Phalacrocorax atriceps) from the South Orkney Islands. British Antartic Survey Bulletin, No. 30: $106-108$.

CROXALL, J. P., 1979. Distribution and population changes in the Wandering Albatross Diomedea exulans L. at South Georgia. Ardea, 67: 15-21.

CROXALL, J. P. \& FURSE, J. R., 1980. Food of Chinstrap Penguins Pygoscelis antarctica and Macaroni Pcnguins Eudyptes chrysolophus at Elephant Island group, South Shetland Islands. Ibis. 122: 237-245.

CROXALL, J. P. \& KIRKWOOD, E. D., 1979. The Breeding Distribution of Penguins on the Antartic Peninsula and the Islands of the Scotia Sea. Cambridge: British Antarctic Survey.

CROXALL, J. P. \& PRINCE, P. A., 1979. Antarctic seabird and seal monitoring studies, Polar Record, 19: $573 \rightarrow 595$.

CROXALL, J. P. \& PRINCE, P. A., 1980. The food of Gentoo Penguins Pygoseleis papua and Marcaroni Penguins Eudyptes chrysolophus at South Georgia. Ibis, 122: 245-253.

FOXTON, P., 1956. The distribution of the standing crop of zooplankton in the Southern Ocean. 'Discovery' Reports, 28: 191-236

FOXTON, P., 1964. Seasonal variations in the plankton of Antarctic waters. In R. Carrick, M. W. Holdgate \&c J. Prevost (Eds.), Biologie Antarctique: 31 1-318. Paris: Hermann.

HARRIS, M. P., 1969. Breeding seasons of seabirds in the Galapagos Islands. Journal of Zoology, 199: 145-165.

HART, T. J., 1942. Phytoplankton periodicity in Antarctic surface waters. 'Discovery' Reports, 21: 261-356.

HUNTER, I., 1979. Burrow-dwelling petrel survey and census, Bird Island, South Georgia. Progress Report 1978-79. British Antarctic Survey unpublished manuscript.

HUNTER, S., 1979. Report on giant petrel fieldwork 1978-79. British Antarctic Survey unpublished manuscript.

IMBER, M. J., 1973. The food of Grey-faced Petrels Pterodroma macroptera gouldi (Hutton), with special reference to diurnal vertical migration of their prey.Joumal of Animal Ecology, 42: 645-662.

IMBER, M. J., 1976. Comparison of the prey of the black Procellaria petrels of New Zealand. New Zealand Journal of Marine and Freshwater Research, 10:119-130.

JOHNSTONE, G. W., 1977. Comparative feeding ecology of the giant petrels Macronectes giganteus (Gmelin) \& M. halli (Mathews). In G. A. Llano (Ed.), Adaptations within Antarctic Ecosystems: 647-668. Washington: Smithsonian Institution.

KOOYMAN, G. L., 1975. The physiology of diving in penguins. In B. Stonehouse (Ed.), The Biology of Penguins. 115-137. London: Macmillan.

KOOYMAN, G. L., DRABEK, C. M., ELSNER, R. \&C CAMPBELL, W. B., 1971. Diving behaviour of the Emperor Penguin, Aptenodytes forsteri. Auk, 88: 775-795.

KURODA, N. H., 1967. Morpho-anatomical analysis of parallel evolution between diving petrel and ancient auk, with comparative osteological data of other species. Miscellaneous Reports of the Yamashina Institute of Ornithology and Zoology, 5, 2(28): 111-137.

LACAN, F., 1971. Observations écologiques sur le pétrel de Wilson (Oceanites oceanicus) en Terre Adélie. Oiseau Revue de Française Ornithologie, 41, Special number: 65-89.

LACK, D., 1934. Habitat distribution in certain Icelandic birds. Joumal of Animal Ecology, 3: 8 1-90.

LACK, D., 1968. Ecological Adaptations for Breeding in Birds. London: Methuen.

LAWS, R. M., 1960. The Southern Elephant Seal Mirounga leonina on South Georgia. Norsk Hvalfangsttidende, 49: $520-542$.

LeRESCHE, R. E., \& SLADEN, W. J. L., 1970. Establishment of pair and breeding site bonds by young knownage Adelie Penguins Pygoscelis adeliae. Animal Behaviour, 18:517-526. 
PAYNE, M. R., 1977. Growth of a fur seal population. Philosophical Transactions of the Royal Society (B), 279: $67-79$.

PAYNE, M. R., 1979. Growth in the Antarctic Fur Seal Arctocephalus gazella.Journal of Zoology, 187: 1-20.

PAYNE, M. R. \& PRINCE, P. A., 1979. Identification and breeding biology of the diving petrels Pelecanoides georgicus and $P$, urinatrix exsul at South Georgia. New Zealand Joumal of Zoology, 6: 299-318.

PEARSON, T. H., 1968. The feeding biology of seabird species breeding on the Farne Islands, Northumberland. Journal of Animal Ecology, 37:521-552.

PENNYCUICK, C. J., 1969. The mechanics of bird migration. Ibis, 111:525-556.

POTTER, I. C., PRINCE, P. A. \& CROXALL, J. P., 1979. Data on the adult marine and migratory phases in the life cycle of the Southern Hemisphere lamprey, Geotria australis Gray. Environmental Biology of Fishes, 4: $65-69$.

PRINCE, P. A., 1980a. The food and feeding ecology of Blue Petrel (Halobaena caerulea) and Dove Prion (Pachyptila desolata). Journal of Zoology, 190: 59-76.

PRINCE, P. A., 1980b. The food and feeding ecology of Grey-headed Albatross Diomedea chrysostoma and Blackbrowed Albatross D. melanophris. Ibis, 122.

PRINCE, P. A. \& PAYNE, M. R., 1979. Current status of birds at South Georgia. British Antarctic Survey Bulletin, No. 48: 103-118.

RICHDALE, L. E., 1965. Biology of the birds of Whero Island, New Zealand, with special reference to the diving petrel and the White-faced Storm Petrel. Transactions of the Zoology Sociely of London, 27: 1-86.

RICKLEFS, R. E., 1973. Patterns of growths in birds. II. Growth rate and mode of development. Ibis, 115: 177-201.

SALOMONSEN, F., 1955. The food production of the sea and the annual cycle of Faeroese marine birds. Oikos, 6: 92-100.

SCHREIBER, R. W. \& ASHMOLE, N. P., 1970. Seabird breeding seasons at Christmas Island, Pacific Ocean Ibis, $112: 363-394$.

SERGEANT, D. E., 1951. Ecological relationships of the guillemots Uria aalge and Uria lomvia. Proceedings of the International Omithological Congress $X, 1959$ (1951):578-587.

SMITH, R. I. L. \& TALLOWIN, J. R. B., 1980. The distribution and size of King Penguin rookeries on South Georgia. British Antartic Survey Bulletin, No. 49:259-276.

STONEHOUSE, B., 1960. The King Penguin Aptenodytes patagonica of South Georgia. I. Breeding behaviour and development. Scientific Report of the Falkland Islands Dependencies Survey, No. 23: I-81.

STONEHOUSE, B., 1967. The general biology and thermal balances of penguins. Advances in Ecological Research, 4:131-196.

THORESEN, A. C., i969. Observations on the breeding behaviour of the diving petrel Pelecanoides $u$. urinatrix (Gmelin). Notornis, 16:241-260.

TICKELL, W. L. N., 1962. The Dove Prion, Pachyptila desolata Gmelin. Scientific Report of the Falkland Islands Dependencies Survey, No. 33: 1-55.

TICKELL, W. L. N., 1967. Movements of Black-browed and Grey-headed Albatrosses in the South Atlantic. Emu, 66:357-367.

TICKELL, W. L. N., 1968. The biology of the great albatrosses, Diomedea exulans and Diomeda epomophora. In O. L. Austin, Jr. (Ed.) Antarctic Bird Studies, Antarctic Research Series, 12: 1-55. Washington: American Geophysical Union.

TICKELL, W. L. N. \& PINDER, R., 1967. Breeding frequencies in the albatrosses Diomedea melanophris and $D$. chrysostoma. Nature, 213:315-6.

WARHAM, J, 1977. Wing loading, wing shapes and tight capabilities of Procellariiformes. New Zealand Journal of Zoology, 4:73-83.

\section{APPENDICES}

\section{Appendix 1. Selected measurements of penguins breeding at South Georgia}

\begin{tabular}{lccccc}
\hline Species & $\begin{array}{c}\text { Body } \\
\text { weight } \\
(\mathbf{k g})\end{array}$ & $\begin{array}{c}\text { Flipper } \\
\text { area } \\
\left(\mathrm{cm}^{2}\right)\end{array}$ & $\begin{array}{c}\text { Culmen } \\
\text { length } \\
(\mathrm{mm})\end{array}$ & $\begin{array}{c}\text { Culmen } \\
\text { width } \\
(\mathrm{mm})\end{array}$ & $\begin{array}{c}\text { Culmen } \\
\text { depth } \\
(\mathrm{mm})\end{array}$ \\
\hline King Penguin & 15.0 & 159 & 133 & 40 & 37 \\
Gentoo Penguin & 5.8 & 103 & 52 & 43 & 44 \\
Macaroni Penguin & 4.8 & 78 & 57 & 33 & 39 \\
Rockhopper Penguin & 2.5 & 57 & 44 & 27 & 33 \\
Chinstrap Penguin & 4.1 & 73 & 49 & 31 & 39 \\
\hline
\end{tabular}

All figures are mean values for both sexes combined. Flipper area from Stonehouse (1967). Culmen width and depth measured at base. 
Appendix 2. Selected measurements of albatrosses and petrels at South Georgia

\begin{tabular}{|c|c|c|c|c|c|c|c|c|}
\hline Species & $\begin{array}{c}\text { Body } \\
\text { weight } \\
\text { (g) }\end{array}$ & $\begin{array}{l}\text { Wing } \\
\text { area } \\
\left(\mathrm{cm}^{2}\right)\end{array}$ & $\begin{array}{l}\text { Wing } \\
\text { loading } \\
\left(\mathrm{g} \mathrm{cm}^{-2}\right)\end{array}$ & $\begin{array}{l}\text { Aspect } \\
\text { ratio }\end{array}$ & $\begin{array}{l}\text { Buoyancy } \\
\text { index }\end{array}$ & $\begin{array}{l}\text { Culmen } \\
\text { length } \\
\text { (mm) }\end{array}$ & $\begin{array}{l}\text { Culmen } \\
\text { width } \\
\text { (mm) }\end{array}$ & $\begin{array}{l}\text { Culmen } \\
\text { depth } \\
\text { (mm) }\end{array}$ \\
\hline Wandering Albatross & 8727 & 4337 & 2.00 & 15.6 & 3.2 & 166 & 45 & 63 \\
\hline Black-browed Albatross & 3788 & 2682 & 1.41 & 14.9 & 3.3 & 117 & 28 & 50 \\
\hline Grey-headed Albatross & 3788 & 2389 & 1.59 & 15.3 & 3.1 & 114 & 27 & 44 \\
\hline $\begin{array}{l}\text { Light-mantled Sooty } \\
\text { Albatross }\end{array}$ & 2840 & 3226 & 0.88 & - & 4.0 & 110 & 23 & 35 \\
\hline Southern Giant Petrel & 5165 & 2748 & 1.87 & - & 3.2 & 95 & 40 & 39 \\
\hline Northern Giant Petrel & 5212 & 2846 & 1.83 & 11.9 & 3.0 & 97 & 42 & 40 \\
\hline Cape Pigeon & 433 & 630 & 0.69 & 9.2 & 3.3 & 31 & 16 & 13 \\
\hline Snow Petrel & 259 & 583 & 0.44 & - & 3.8 & 20 & 10 & 12 \\
\hline Dove Prion & 168 & 423 & 0.69 & 8.5 & 3.7 & 80 & 15 & 14 \\
\hline Blue Petrel & 193 & 392 & 0.49 & 10.8 & 2.4 & 27 & 10 & 10 \\
\hline White-chinned Petrel & 1368 & 1455 & 0.94 & 12.1 & 3.4 & 52 & 21 & 20 \\
\hline Wilson's Storm Petrel & 38 & 151 & 0.25 & - & 3.8 & 13 & 8 & 7 \\
\hline $\begin{array}{l}\text { Black-bellied Storm } \\
\text { Petrel }\end{array}$ & 53 & 226 & 0.23 & 6.5 & 4.0 & 15 & 8 & 6 \\
\hline $\begin{array}{l}\text { Grey-backed Storm } \\
\text { Petrel }\end{array}$ & 29 & 140 & 0.24 & 6.4 & 3.9 & 13 & 5 & 5 \\
\hline $\begin{array}{l}\text { South Georgia Diving } \\
\text { Petrel }\end{array}$ & 107 & 183 & 0.58 & 6.9 & 2.6 & 15 & 8 & 8 \\
\hline Common Diving Petrel & 183 & 174 & 0.76 & 7.0 & 2.5 & 16 & 8 & 10 \\
\hline
\end{tabular}

Body weights and bill measurements are mean values for both sexes combined. Wing areas and aspect ratios from Warham (1977), except for Blue Petrel and South Georgia Diving Petrel. Buoyancy Index is square root of wing area divided by cube root of weight. Culmen width and depth measured at base. 